University of Pennsylvania Carey Law School

Penn Law: Legal Scholarship Repository

Faculty Scholarship at Penn Law

3-13-2014

\title{
Distributional Consequences of Public Policies: An Example from the Management of Urban Vehicular Travel
}

\author{
Winston Harrington \\ Resources for the Future \\ Elena Safirova \\ Resources for the Future \\ Conrad Coleman \\ York University \\ Sébastien Houde \\ Stanford University \\ Adam M. Finkel \\ University of Pennsylvania
}

Follow this and additional works at: https://scholarship.law.upenn.edu/faculty_scholarship

Part of the Behavioral Economics Commons, Energy and Utilities Law Commons, Policy Design,

Analysis, and Evaluation Commons, Public Economics Commons, Public Policy Commons, Social Policy

Commons, State and Local Government Law Commons, Urban, Community and Regional Planning

Commons, and the Urban Studies and Planning Commons

\section{Repository Citation}

Harrington, Winston; Safirova, Elena; Coleman, Conrad; Houde, Sébastien; and Finkel, Adam M., "Distributional Consequences of Public Policies: An Example from the Management of Urban Vehicular Travel" (2014). Faculty Scholarship at Penn Law. 1299.

https://scholarship.law.upenn.edu/faculty_scholarship/1299

This Article is brought to you for free and open access by Penn Law: Legal Scholarship Repository. It has been accepted for inclusion in Faculty Scholarship at Penn Law by an authorized administrator of Penn Law: Legal Scholarship Repository. For more information, please contact PennlawIR@law.upenn.edu. 


\title{
Distributional Consequences of Public Policies: An Example from the Management of Urban Vehicular Travel
}

\author{
Winston Harrington, Elena Safirova, Conrad Coleman, \\ Sébastien Houde, and Adam M. Finkel
}

\begin{abstract}
This paper uses a spatially disaggregated computable general equilibrium model of a large US metropolitan area to compare two kinds of policies, "Live Near Your Work" and taxation of vehicular travel, that have been proposed to help further the aims of "smart growth." Ordinarily, policy comparisons of this sort focus on the net benefits of the two policies; that is, the total monetized net welfare gains or losses to all citizens. While the aggregate net benefits are certainly important, in this analysis we also disaggregate these benefits along two important dimensions: income and location within the metropolitan area. The resulting identification of gainers and losers with these policies, though undoubtedly important to matters such as fairness and political feasibility, are rarely made. We find that these distributional effects are quite sensitive to the details of policy design.
\end{abstract}

Key Words: growth management, urban planning, urban transportation, smart growth

JEL Classification Numbers: R13, R48, R52

(C) 2014 Resources for the Future. All rights reserved. No portion of this paper may be reproduced without permission of the authors.

Discussion papers are research materials circulated by their authors for purposes of information and discussion. They have not necessarily undergone formal peer review. 


\section{Contents}

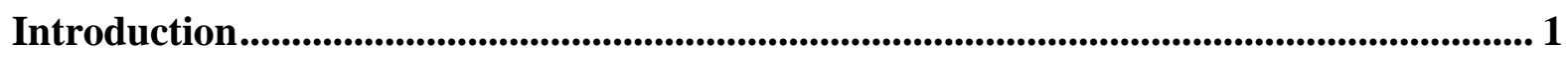

I. Curbing Urban Sprawl ..................................................................................................................... 5

II. Model Description....................................................................................................................................... 6

START

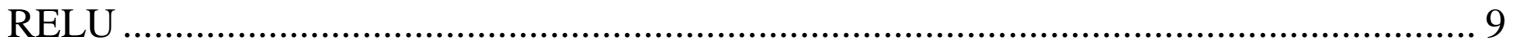

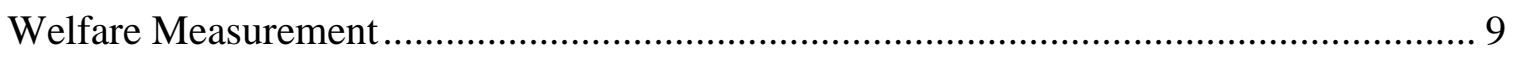

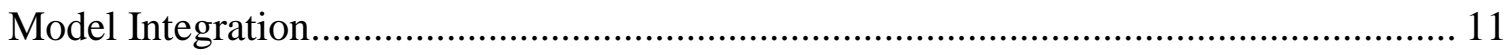

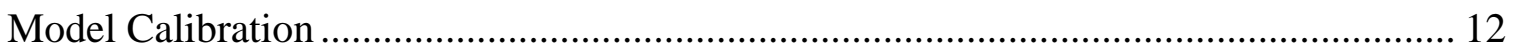

III. Policy Modeling ...................................................................................................................................... 14

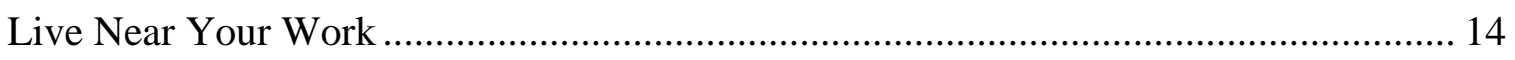

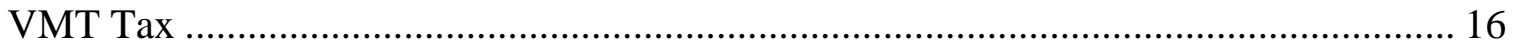

IV. Results................................................................................................................................................. 16

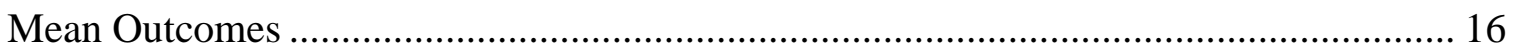

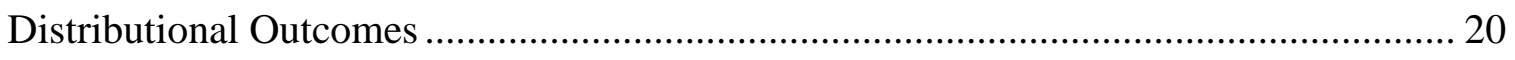

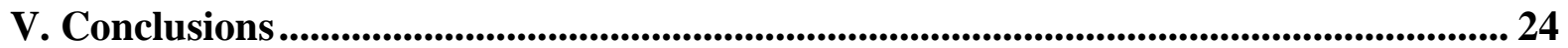

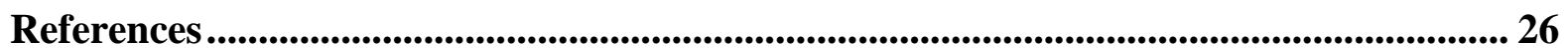

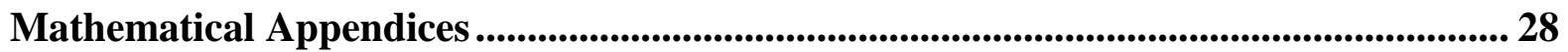

Tables …......................................................................................................................................................... 41

Figures........................................................................................................................................................ 51 


\title{
Distributional Consequences of Public Policies: An Example from the Management of Urban Vehicular Travel
}

\author{
Winston Harrington, Elena Safirova, Conrad Coleman, \\ Sébastien Houde, and Adam M. Finkel*
}

\section{Introduction}

This paper describes a set of experiments using a detailed, regional computable general equilibrium (CGE) model to examine and compare the costs and benefits of a set of local policies to implement "smart growth," principally by attempting to discourage the low-density development patterns characteristic of urban sprawl. A particular focus of the research is to examine the distribution of those costs and benefits over space and income groups and the manner in which the distribution of outcomes is affected by details of the various policies. This research seeks to contrast "naïve" presentations about costs and benefits (i.e., that costs and benefits are uniformly distributed, an assumption made either because analysts believe this will be the case or because a lack of information precludes any other assumption) with more detailed analyses of how different subpopulations will actually fare.

Although it is recognized that public policies can have very disparate impacts on the individuals that are subject to them, the issue of how benefits and costs are distributed has often been given short shrift in policy evaluation, especially in the evaluation of health, safety, and environmental regulation. And though many regulatory impact analyses (RIAs) consider the interindividual distribution of risks reduced (benefits), far fewer of them consider the distribution of costs; those that do almost always stop short of analyzing effects on consumers, considering only the variation in costs at the producer level, by industry sector and/or firm size (Finkel 2013). The principal criteria now used in public policy evaluations are (a) the "net benefit" criterion, which is derived by estimating the sum of benefits to all parties less the costs (regardless of the concentration of benefits or costs and regardless of who enjoys the benefits or pays the costs) and (b) its close relative, the benefit-cost ratio.

\footnotetext{
*Winston Harrington, Resources for the Future (harrington@rff.org); Elena Safirova, US Geological Survey; Conrad Coleman, University of York, Canada; Sebastien Houde, University of Maryland; Adam M. Finkel, University of Pennsylvania.
} 
The original rationale for the net benefits criterion - also called the Kaldor-Hicks criterion in welfare economics - is the more restrictive Pareto criterion, which defines welfare improvement as that achieved by an action that makes at least one member of the polity better off without making anyone worse off. Private transactions between individuals, at least those that do not involve externalities, are welfare-improving in the Pareto sense, because they are consensual. However, it is the rare public policy that does not have adverse implications for at least one person. What Kaldor and Hicks observed was that if the aggregated gains to the winners were enough to compensate the losers, then any policy in which the total benefits exceed the total costs would improve welfare after such compensatory payments were made. But because transaction costs would make actual transfer payments impractical, actual compensation was replaced with hypothetical compensation, yielding the net benefits criterion. Although that change made it possible to rank every policy option, the welfare implications of such a ranking were no longer apparent. A policy could have positive net benefits and still have many more losers than winners, and although the sum of winners' gains would exceed the losses, no one could say that as a whole, society was better off.

Indeed, if such a policy were subject to a popular-vote referendum, with citizens given accurate information about who would gain and who would lose, it would, by definition, have more opponents than supporters, and would fail such a "one person, one vote" test. The welfare implications of positive net benefits would be especially murky if the losers tended to be poorer than the winners. Conventional utility theory, which lies at the basis of welfare economics, usually posits that the marginal utility of income decreases as income increases. In other words, use of the net benefits criterion fails to account for the possibility that income losses to the poor would reduce their satisfaction more than income gains to the rich would improve theirs. In such a scenario, positive net benefits on a monetary scale would mask negative net benefits when dollars are expressed in units of utility - even on an aggregate basis that ignores distributional and equity issues.

Given these problems, why have the net benefits and benefit-cost ratio criteria become the principal standards for rating proposed public policies? Several possibilities come to mind. First, these criteria are not zero-one outcomes. The margin by which benefits exceed costs - and, even more, the size of the benefit-cost ratio-is an important part of the indicator. It is natural to think that the greater the ratio of expected benefits to costs, the more likely the policy will be to have positive net benefits for the majority, or the vast majority, or even for nearly all affected individuals. Second, policymaking is not a one-off event; governments make policy decisions repeatedly on a variety of issues. Some may think of these decisions as independent events, such 
that winners and losers of successive interventions would not be the same. If so, then ensuring that the net benefits criterion is met for each policy would increase the likelihood that most individuals would benefit from the entire portfolio of policies. Third, many policies, especially those involving economic incentive approaches, are not easy to improve in distributional terms without interfering with their efficiency properties. In such cases, some may wish to leave the new policy alone and seek some kind of compensation to losers through the tax system.

Still, for several reasons it is important to understand the distributional consequences of public policies. For one thing, such knowledge is a prerequisite if policymakers are to make adjustments to compensate losers. In addition, knowledge of distributional outcomes can be an aid to policy design, for often it is possible to make alterations to policies that have little effect on total benefits or costs yet can materially affect the distribution of outcomes. Indeed, information on distributional outcomes of major policies would seem to be an essential element of an open society. People deserve to have an idea of how impending policy changes will affect them. Yet distributional analyses of public policies are often noticeable mainly by their absence. For example, a study of recent RIAs of proposed social regulations found that, for the vast majority, a distributional analysis was either rudimentary or missing (Cranor and Finkel 2013), particularly on the "cost side."

Even when a distributional analysis is carried out, it is usually done only for income. When distributional considerations are raised, they are usually done so under the banner of fairness. Unfortunately, what is "fair" usually has no obvious definition; or rather, it has many definitions depending on who is defining it. In practice, fairness often is considered synonymous with progressivity; in other words, a fair policy should not exacerbate the maldistribution of wealth. Thus, when policy analysts consider the distribution of net benefits of proposed policies, the focus is often on the distribution of benefits and costs by income group. But many other potentially identifiable characteristics of individuals or households - such as residential location, age, occupation, and marital status - could affect their gains or losses and could, therefore, make a material difference in outcomes for a particular policy.

Our objective in this paper is to illustrate how a disaggregated general equilibrium model could shed light on distributional outcomes of public policies. To do so requires a modeling apparatus that is able to disaggregate the agents affected by the policy, particularly regulated firms and affected households, into groups of policy interest. Firms, for example, could be disaggregated by size or location, among other things, and households could be disaggregated by income, location, or other covariates. For a health, safety, or environmental regulation that imposes compliance costs on firms, the model could first disaggregate the costs firms bear, and 
then model how different subsectors of industry pass on those costs to the different kinds of households that are their customers.

Very briefly, the policies examined here include three variants of so-called "live near your work" (LNYW) programs, which provide modest subsidies to encourage homeowners to relocate — or to change employment location - to reduce their commuting costs. ${ }^{1}$ As explained further below, these three policies differ by who is eligible for the subsidy. A fourth policy considered here is a tax imposed on total miles traveled by motorists in a metropolitan area. The idea behind this vehicle miles traveled (VMT) tax is that the higher cost of travel will induce motorists to change travel habits in a variety of ways, not only by moving homes or changing jobs, but through the frequency of and distance traveled for shopping and other kinds of trips as well as by switching to other travel modes, such as bus or rail transit. All of these policies rely on economic incentives rather than direct regulation to achieve their objectives.

Both LNYW and VMT policies offer a mix of benefits and costs, so the overall picture of net benefits for each policy is not obvious. The principal cost of LNYW is the cost of providing the subsidy, which is shared by everyone in the community. These revenues directly benefit those who are in a position to accept the subsidy, who also benefit from shorter daily commutes. In turn, less traffic may offer congestion relief, fewer accidents and better air quality to the general population. The main cost of the VMT tax is the tax itself, which imposes costs on motorists in direct proportion to their driving. The benefits derive from the overall reduction in motor vehicle use that is supposed to ensue, such as reduced congestion and accidents, improved air quality, and of course the tax revenue itself, which can be used to produce other public goods or to replace other taxes with high excess burdens.

Despite their overall similarities, these policies differ considerably in their overall net welfare outcomes as well as their distribution of those outcomes across various groups of agents. Of these four, we find that benefits exceed costs only for the VMT tax, and only at some tax rates. If the tax rate is too high, too much travel is discouraged and the net losses of the policy exceed the gains. Our results suggest that, at all subsidy rates, the LNYW policies are inefficient and net gains are exceeded by the costs. Policymakers often choose inefficient policies if they result in payoffs in other dimensions, particularly if they address distributional concerns.

\footnotetext{
${ }^{1}$ Households with two full-time employed individuals are eligible for such programs if either individual meets the employment location test. In our model, agents are individual workers, not households, so the issue does not arise.
} 
However, in this case, we find that the distributional effects of the LNYW policies are, at best, only mildly progressive and therefore do not provide any fairness justification for policies that also fail a Kaldor-Hicks test. On the other hand, some permutations of the VMT tax are actually rather progressive, and therefore provide further justification (beyond the positive net benefits) for pursuing them.

The plan of the paper is as follows. Section I provides background and a selective review of the literature on the costs and other consequences of urban sprawl and the measures that have been undertaken to prevent it. In Section II, we describe LUSTRE (Land Use, Surface Transportation, and Regional Economics), a highly disaggregated spatial CGE model of the Washington, DC, metropolitan area developed by Resources for the Future to simulate urban transportation and land use policies in a complex and realistic setting. LUSTRE is the platform we use to compare policy outcomes. Section III describes the four policies we examine and explains how these policies are represented in LUSTRE. We present, discuss, and compare our results in Section IV, first by showing the aggregate (mean) outcomes and then by showing the disaggregated (distributional) outcomes for both policies. We draw conclusions in Section V.

\section{Curbing Urban Sprawl}

Smart growth proponents all over the country have compiled a long list of policies and strategies that should, in principle, help curb urban sprawl. Although such policies vary widely, they generally adhere to major themes of mixed land uses, the provision of alternative transportation choices, and the promotion of compact building design. The opponents of smart growth, on the other hand, assert that such intervention does not reflect consumer preferences and infringes on personal freedom. Both sides, ironically, have claimed at various times that the opposing policy can increase traffic congestion and air pollution, reduce housing affordability, result in socially undesirable levels of density, increase public service costs, and require wasteful transit subsidies. The debate remains highly contentious, in part because few analytical tools are suitable for settling the issues raised. In this respect, the smart growth debate mirrors the typical controversies about health, safety, and environmental regulations more generally — with arguably optimistic estimates of lives saved and jobs created vying with dire predictions of burdensome costs and unemployment (Coglianese et al. 2013).

For many years, urban economics research has attempted to come up with formal models that can shed some light on the issues. First of all, urban economists have tried to build models that show what sorts of market failures lead to the exacerbation of sprawl (Brueckner 2000, 2001). They have looked at possible welfare implications of particular policies, mostly growth 
controls. The standard conclusion from that literature is that an extreme form of growth control, such as urban growth boundaries (UGB), in the setting of a standard monocentric city model with no explicit modeling of production, can serve as a second-best policy for internalizing congestion externalities. In other words, such a policy is less economically efficient than a set of optimal congestion tolls but more feasible politically.

However, when the monocentricity assumption is relaxed, both congestion tolls and UGB might have unexpected effects. In a real city, a UGB might exacerbate sprawl as settlement is encouraged beyond the outer extent of the growth boundary. And rather than encourage more residential development in the city center, congestion fees may instead encourage low-density employment on the periphery.

Congestion tolls, in particular, have been as unpopular among local politicians and commuters as they have been lauded by urban and transportation economists for their efficiency properties. But in more realistic settings, even optimal kinds of tolls can easily become suboptimal or even inefficient when other types of externalities and/or frictions are present in the system. Some examples of such externalities and frictions include agglomeration economies (Arnott 2007; Safirova 2002), increased congestion on untolled facilities, and labor taxes (Parry and Bento 2001). When studying second-best and third-best urban policies, one should take the presence and interaction of the significant external effects into account if one aspires to produce policy-relevant results. In addition, the presence of real-world complicating factors - such as transportation networks, realistic geographic structure or urban areas, and the presence of heterogeneous agents - could produce outcomes that are significantly different from those obtained using (relatively) simple geometries and theoretical models. Of course, our "real-world" model will be painfully simplistic compared to the actual set of interactions that take place, but it should suggest (a) the importance of elements that the simple theoretical urban models leave out and (b) the possibility that proposing effective and efficient second-best policies can be more challenging than simple models can predict.

\section{Model Description}

LUSTRE consists of two independent, spatially disaggregated models that have been yoked together by Resources for the Future to create a detailed CGE model of the economy of the Washington, DC, metropolitan region. LUSTRE's two components - a simplified transportation sketch planning model (START) and a CGE Regional Economy and Land Use (RELU) model - communicate with each other to simulate land use and transportation policies in a realistic and detailed model of land use, transportation, and regional economic development. In 
this section, we provide a short description of the integrated model and characterize the baseline equilibrium used in this paper.

\section{START}

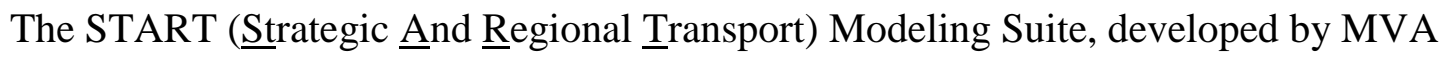
Consultancy, has been applied to a range of urban centers in the United Kingdom, including Birmingham, Edinburgh, and South England (Croombe et al. 1997; May et al. 1992). More recently, this model was calibrated for Washington, DC, and was used to conduct policy simulations of gasoline taxes (Nelson et al. 2003), High-Occupancy Toll (HOT) lanes (Safirova et al. 2003), and congestion pricing (Safirova et al. 2004; Safirova et al. 2005); to compute network-based marginal congestion costs of urban transportation (Safirova et al. 2007); and to evaluate the benefits of public transit (Nelson et al. 2007).

START is designed to predict the transportation-related outcomes of different transportation policies. In this model, "policies" refer to combinations of different transportation elements, which in broad terms encompass changes in road or public transit capacity (e.g., new infrastructure); operating conditions; and tolls, fares, and other fees. Most local transportation models have very detailed supply sides - for example, the model used in the Washington, DC, metro area has about 2,000 zones plus a detailed road network - and rather rudimentary demand modules. In contrast, START has a limited zonal structure and an aggregated representation of the supply side combined with a very detailed demand side. With this structure, the model runs to completion after a run time that is short (about 30 minutes) relative to more conventional models; this provides an opportunity to conduct and compare a large number of policy simulations to better understand their potential consequences.

The Washington START model has 40 travel zones with three stylized transportation links in each zone (inbound, outbound, and circumferential) and a number of other "special" links that represent highway segments and bridges. Six main corridors (I-270, I-95, and US-50 in Maryland and I-66, I-95, and the Dulles Toll Road [VA-267] in Northern Virginia) connect the outer suburbs to the central region within the circular I-495/I-95 ring known as the Beltway (Figure 1a). The rail network combines the Washington Metrorail system and suburban heavy rail systems (Maryland Rail Commuter and Virginia Railway Express). Rail travel occurs on routes, which are modeled as series of rail links that represent segments of the rail network. Bus travel is represented by a highly stylized route network, with bus accessibility in any zone determined by the density of stops, frequency of service, and reported bus travel times. Transit crowding costs and parking search costs are explicitly included in the model. The model also 
accounts for existing high-occupancy vehicle (HOV) lanes on I-95, I-395, I-66, and VA-267 in Northern Virginia, as well as I-70 and US-50 in Maryland. Moreover, we recently have made several improvements to transit modeling, such as incorporating park-and-ride facilities for rail trips, placing buses on the links used by other on-road vehicles (so that buses are affected by and contribute to road congestion), and a creating a more detailed treatment of the rail network.

This rather aggregated supply-side representation is combined with a detailed demandside structure. START features multiple agent types (up to eight in the current implementation) that can differ by income or any other demographic characteristic. The model includes six trip purposes: home-based work (HBW), home-based shopping (HBS), home-based other, nonhomebased work, nonhome-based other, and freight. Home-based trips either originate or terminate at home. The model distinguishes four travel modes: single-occupancy vehicle (SOV), HOV, transit (which has two submodes, bus and rail), and nonmotorized (walking and bicycling). It also represents three time periods: morning peak, afternoon peak, and off peak.

START takes HBW and freight trip demands by demographic segment and residential location as exogenous; it takes trips for other home-based purposes as endogenous but highly inelastic. A travel decision is modeled as a set of sequential decisions - for example, whether to travel, then the purpose of the trip, then the destination, then the time of day, then the modespecified as a nested multinomial logit model. The utility functions at each nest are linear in generalized costs (the combined monetary and time costs of travel). The value of time is a function of the travelers' wage rate and varies by trip purpose. Crowding on public transit routes also induces an artificial time penalty, which is tantamount to an increased travel time. For home-based trip purposes, agents choose in successive nests whether to generate a trip (for purposes with endogenous demand), then destination, mode, time of day, and route. The utility for each nest $i$ is given by $U_{i}=A_{i}-\beta p_{i}$, where $A_{i}$ is a calibrated value representing idiosyncratic preferences, $\beta$ is an exogenous response parameter (indexed by trip purpose and nest level), and $p_{i}$ is a generalized cost of travel that combines time and money costs explicitly modeled in the supply module. Nonhome-based trip demands are an explicit function of home-based trip numbers at the model level. Agents choose the time of day and route in successive nests.

The overall structure of START is an iterative one. The trips computed in the demand module are loaded onto the supply network. The supply network uses the loads to compute costs of travel, which are passed back to the demand module. This process iterates until the costs of travel converge to equilibrium values. 
To integrate START with the RELU model, we made several modifications to the standalone START. First, for the trip purposes that are explicitly modeled in RELU (HBW and HBS trips), the trip-generation and destination nests are removed. Instead, in LUSTRE, RELU generates trip demands and passes these numbers to START (we discuss this in more detail in the integration part of this section). Second, the definitions of shopping trips in RELU and START are mismatched; RELU shopping trips include trips to service locations (e.g., doctor's office or lawyer), while START trips do not. We let each model work with its own definition and make necessary conversions in the integration procedure.

\section{RELU}

RELU was developed by Alex Anas and Elena Safirova with the purpose of creating a theoretically sound modeling tool for policy analysis. RELU is a spatially disaggregated CGE model of a regional economy that is grounded in microeconomic theory and can be used for comprehensive welfare analysis.

In its modeling philosophy, RELU follows the structure of Anas and Xu (1999), although several new features (the presence of several agent types, the explicit possibility of unemployment, the modeling of housing and building stocks, and income and real estate taxes) position the model to tackle complex, realistic problems. In its present calibration, the model features four groups of consumers/workers, four primary industries, and construction/demolition industries, as well as decision-making by landlords and developers. A mathematical description of RELU is provided in the mathematical appendix.

\section{Welfare Measurement}

Each model described above provides a natural way to measure welfare changes resulting from policies. In START, consumer surplus can be computed in a manner consistent with the nested logit tree underlying the decision-making process. At each nest, consumer surplus is computed as a logsum of utilities achieved at each branch of the tree that descends from that nest.

Then the overall welfare is the logsum computed at the top nest:

$$
W=\frac{1}{\beta} \ln \sum_{i} e^{A_{\mathrm{i}}-\beta p_{\tilde{\mathrm{i}}}}
$$


Several caveats apply to the use of this approach in the context of the integrated model. First, because separate welfare measures are computed for each trip purpose as opposed to each agent class (i.e., consumer surplus is computed per trip, not per person), a judgment may have to be made about the relative value of various travel purposes. Second, the model does not provide an easy way to compute the marginal utility of money for the travelers making trip choices. However, we can use a Taylor series approximation to the objective function and use it to find marginal effects. Third, to compute the social surplus of a particular policy, one has to make assumptions about the marginal costs of public funds and about government efficiency when spending public money. Nevertheless, if particular (even ad hoc) assumptions are made, the model provides a relatively straightforward way to evaluate the welfare associated with simulated policies. Some examples are discussed below.

On the other hand, RELU provides a way to compute the economic welfare of consumers/residents without requiring the modeler to make the same ad hoc decisions. In RELU, utility is agent-based; therefore, valuation of travel purposes is internalized. RELU's utility function is log-linear in agent's income, so one can evaluate the marginal utility of income for each choice (equations A5 and A7). Finally, RELU explicitly treats income taxes and can, therefore, compute marginal costs of public funds.

Because the discrete consumer choices in RELU are a nested multinomial logit, the welfare measure in the model can be written as:

$$
W_{f}=\frac{1}{\lambda_{f}^{H}} \ln \sum_{w} e^{\lambda_{f}^{H} V_{w \mid f}}
$$

In LUSTRE, we adopt the RELU definition of welfare measurement. In fact, the structure of the integrated model stipulates that RELU, and therefore its welfare measure, serves as a tool for the comprehensive evaluation of the changes in the economy, including the transportation sector, and for the most part this evaluation is indeed comprehensive.

Furthermore, because the indirect utility function in $\operatorname{RELU}(\tilde{U}$, equation A5) is a function of endogenous economic and transportation variables, we can decompose the welfare change to evaluate how each of those variables affects welfare.

The decomposition of the welfare gains is approximated using the linear Taylor polynomial for the welfare measure (i.e., the sum of the partial derivatives of the welfare function, times the variation from the baseline to the simulation, of the endogenous economic 
and transportation variables). Following this approach, we get a formula for the decomposition of the total welfare gain $(\Delta W)$ :

$$
\begin{aligned}
\Delta W_{f}= & \Delta \operatorname{TRD}_{f} \frac{\partial W}{\partial T R D_{f}}+\Delta D I V_{f} \frac{\partial W}{\partial D I V_{f}}+\sum_{j} \Delta w_{j \mid f, w=E} \frac{\partial W}{\partial w_{j \mid f}}+ \\
& \sum_{z} \Delta p_{\Re|f| f} \frac{\partial W}{\partial p_{\Re z \mid f}}+\sum_{i k} \Delta R_{i k \mid f} \frac{\partial W}{\partial R_{i k \mid f}}+\sum_{i j} \Delta G_{i j \mid f}^{\text {working }} \frac{\partial W}{\partial G_{i j \mid f}^{\text {working }}}+ \\
& \sum_{i z} \Delta G_{i z \mid f}^{\text {shopping }} \frac{\partial W}{\partial G_{i z \mid f}^{\text {shopping }}}+\phi_{f}
\end{aligned}
$$

In equation (3), the first term represents welfare gains from the changes in toll revenues redistributed (the surplus of transit fares is included), the second term accounts for changes in dividends due to the change in the real estate values, the third term represents changes in wages, the fourth term accounts for changes in retail prices, the fifth term comes from changes in rents, the sixth term represents changes in commuting costs, the seventh term stands for changes in the costs of shopping trips, and the last term is a correction term due to the first-order approximation. The formula allows one to determine how changes in physical outcomes (such as wages or transportation costs) contribute to overall welfare change. The mathematical appendix provides details on the formulation of each term.

\section{Model Integration}

In LUSTRE, RELU and START are integrated at the level of the individual agent; this feature makes the integrated program well-suited for testing the behavioral response to either policies or economic scenarios. Moreover, this integration and the fact that RELU and START operate at the same level of geographic disaggregation make the integrated model very precise in passing information between the two modules. The integration is implemented using an auxiliary program called "Bridge" that assists in data exchange between the two models by aggregating and disaggregating them as needed. To help the reader better understand the mechanism of interactions between the two models, we describe one loop of the iterative procedure.

First, RELU takes time costs and monetary costs of travel—disaggregated by skill class, trip purpose, and origin-destination pair - as given. The RELU simulation yields, in addition to other land use and economic effects, trip demands at the same level of disaggregation given above. The Bridge disaggregates those trip demands further by mode, time period, and route, based on their calibrated distribution, to provide START with an initial guess of this further 
disaggregation of trip demands. The Bridge also translates RELU-determined wage rates into a value of time for START. By minimizing travel costs at the level of the individual trip, START iteratively redistributes trips among routes, time periods, and modes; at each iteration, it computes generalized costs of travel. START terminates when the costs of travel converge to equilibrium values. At this point, the Bridge aggregates the equilibrium generalized travel costs over routes, time periods, and modes, splits the costs into time and money elements, and passes this new set of transportation costs to RELU. With these new transportation costs, RELU finds new equilibrium land use and economic values, including new travel demands and wages. The Bridge processes these new travel demands and wages as described above, START runs again, and so on. The process continues until both trip demands and costs converge to values that do not change (more than a specified tolerance) between iterations.

\section{Model Calibration}

The integrated model is calibrated to the year 2000 for the Washington, DC, metropolitan area. The population of potential workers (the active population) is divided into four groups, with each group representing a different skill class. All workers with the same skill class and living in the same zone have the same wage. Across zones, the wages for workers of the same skill class may differ, but not by enough to cause categories to overlap. Nonworkers do not receive wages, but they do receive nonwage income.

To calibrate the model, a variety of data sources have been used. Data on residential and workplace patterns, wages, and incomes were extracted from the Census Transportation Planning Package (CTPP) and supplemented by the Consumer Expenditure Survey; prices and production volumes are based on data obtained from the Bureau of Labor Statistics; housing consumption data and residential rents came from the American Housing Survey; and land use data were collected from the local and county governments in the metropolitan area. On the transportation side, we merged the data from the CTPP with data from the 1994 Travel Survey, scaled up to the 2000 levels of travel demand. The Metropolitan Washington Council of Governments version 1 transportation planning model and the data from aerial photography (Metropolitan Washington Council of Governments 1999) were used to calibrate road link speeds.

In the calibrated baseline equilibrium, our area of study has an active population of about $4,139,000$ heads of household, who comprise one of the main groups of agents in the model and of whom 76.7 percent are employed (Table 1a). This population is divided into four skill classes, with every agent in each class having the same income. The proportion of agents in each skill class is somewhat unevenly distributed, with more than a third in the lowest class (skill class 1) 
and slightly more than 10 percent in the highest class. These apportionments were based on the CTPP and represent an aggregation of its income bins. Table $1 \mathrm{~b}$ shows the population in each of the 36 interior zones in the model (the 4 exterior zones are omitted) as well as the distribution of residents in each zone by skill class. A map of these zones is shown in Figure 1. As shown, the zones become larger in area as one approaches the periphery of the region; in terms of population size, they range from 10,000 to 334,000 residents. Each zone contains a mix of residents in the four skill classes; for example, skill class 1 residents make up at least 28 percent of each zone.

As Table 2 shows, in the baseline equilibrium, average incomes range from nearly $\$ 16,000$ (skill class 1 ) to a bit more than $\$ 90,000$ (skill class 4 ). These average incomes include both employed and unemployed workers in each class as well as unearned income, which is primarily interest and capital gains in level 4 and welfare payments in level 1. On average, consumers spend about 20 percent of their net incomes on housing and the rest on consumer goods and services. Marginal state and federal income tax rates range from 14.3 percent for the lowest skill class to 31.5 percent for the highest. Wages vary somewhat from one zone to another across the area of study, but average hourly wages for the four sSkill classes range between $\$ 6.80$ and $\$ 47.00$.

The downtown core, the workplace of 13 percent of the region's workers in the baseline, serves as the destination of more than 15 percent of morning commute trips and 11 percent of off-peak commute trips. On the other hand, the lion's share of rail trips (69 percent) have, as their destination, the downtown core. The role of the city core as a shopping destination is much less prominent, with only about 1 percent of shopping trips destined for downtown locations. Nearly all of these shopping trips to the core are made by core residents, except perhaps for a relatively small number of nonhome-based trips by downtown workers.

LUSTRE is a good platform for examining the distributional outcomes of public policy because of the model's high degree of heterogeneity of baseline attributes of agents. Most important for our purposes are the skill classes of agents, which determine their income, and the agents' locations, which determine their commuting behavior and opportunities. In addition, a random, unobserved element, determined by one of the parameters of the logit utility function, enters the utility function of each agent, and this too can affect how individual agents respond to and are affected by policies. In contrast, most other studies of the effects of the distributional effects of public policies do not go much further than an examination of how outcomes are affected by income. For example, RIAs, which are supposed to report on benefits and costs of proposed regulations, rarely consider the effects of any variables on individual costs. 


\section{Policy Modeling}

\section{Live Near Your Work}

LNYW programs offer financial assistance to homebuyers who choose a home proximate to their place of employment. A variety of such programs are offered by governments at all levels, often in conjunction with lenders such as Fannie Mae and large employers, notably universities. The main purpose of these programs is to promote smart growth development by encouraging residents to give primacy to their commute in choosing their housing location. Some programs have an additional goal of attracting and maintaining a local work force, and thus are targeted at city or public school employees or the employees of a sponsoring private, nongovernmental institution. Others have a distributional objective: to assist low- and moderateincome residents who might otherwise be priced out of desirable in-city neighborhoods. LNYW programs can be found nationwide, and several jurisdictions in the Washington metropolitan area have them. Table 3 gives the characteristics of a sample of these area programs, with emphasis on the ones in or near the Washington metropolitan area.

Because the journey to work is such an important component of urban travel demand, LNYW has the potential to reduce congestion and VMT in the region, especially during rush hour. If implemented in an urban core area that still has a strong concentration of employment, such as Washington, DC, LNYW can also promote infill development, increasing the demand for nearby housing and, in turn, supporting existing local retail establishments. Over a longer time horizon, it could provide incentives for job growth in the core area and encourage further retail development. These prospective developments, at any rate, form the rationale for policies like LNYW.

\section{Modeling LNYW}

For our simulations, we model an LNYW program that provides a closing cost assistance grant. For the "central" simulation of the LNYW policy, we consider a grant that provides a closing cost assistance grant of $\$ 4,000$ to $\$ 12,000$ (throughout the paper, all dollars are 2000 dollars). Our central policy, $\$ 8,000$, is toward the upper limit of the existing programs. To provide an illustrative example and to accommodate the modeling features of LUSTRE, we relax some of the eligibility criteria. For example, because homeownership is not modeled explicitly in LUSTRE, we cannot simulate an LNYW program that restricts the grant to first-time homebuyers. Thus, all individuals meeting the location criteria, described below, receive a grant. In the real world, however, those already meeting the criteria also receive a benefit in that their residential locations become more valuable, so perhaps this is not a significant distortion. Also, 
the exact geographic locations of the buildings within LUSTRE zones are not defined, so it is not possible to consider an eligibility criterion based on a specific home-work distance.

For a first series of simulations, we consider an LNYW program that provides a grant only to the residents living and working in the same zone inside the Beltway (I-495, Figure 1). We refer to this policy as the "Beltway" policy in what follows. This policy is more consistent with the objectives of infill development in that it creates an incentive for residents and, to some extent, firms, to move closer to the center of the Washington Metropolitan area. For a second series of simulations, we make the same assumptions as above, except that only low- to moderate-income individuals (sSkill classes 1 and 2) are eligible for the subsidy; this is the "Beltway12" policy. Finally, in the last LNYW simulation, we assume that all zones of our study area (see Figure 1) participate in the LNYW program and that, to be eligible for the grant, individuals must live and work in the same zone (the "LNYW all-zones" policy). ${ }^{2}$

LNYW is a subsidy; thus the question immediately arises, in LUSTRE as in the real world, where the money is coming from. Various tax schemes can be entertained to make the overall policy package revenue-neutral. However, our previous experience with the model has demonstrated that the results, with respect to both the efficiency of the policy and its distributional effects, are very sensitive to the details of both the subsidy and the revenue-raising scheme. Also, their individual effects are impossible to disentangle. To avoid contaminating the effects of the subsidy by a particular revenue scheme, we simply dispense with the revenue requirement, allowing us to observe the net changes in welfare from the scheme for each agent in the model. If the average welfare change is smaller than the subsidy used to produce it, the subsidy policy is inefficient. In effect, we are assuming that the funds for the subsidy were collected at the costs of public funds equal to zero. Undoubtedly, this assumption is unrealistic. The customary local taxes that would be used to finance LNYW, such as taxes on land, labor, or sales, all have excess burdens and thus will lead to an overstatement of the efficiency of the policy. Under any realistic financing mechanism, the net welfare changes from the policy will be less favorable than those we compute here.

\footnotetext{
2 Obviously, these policies are hypothetical, as each affects parts of two states plus the District of Columbia. No political unit would have the authority to impose such a policy throughout the region. The same is true of the VMT tax discussed subsequently.
} 


\section{VMT Tax}

As an alternative to LNYW, we investigate a VMT tax, which would levy a per-mile tax on motorists based on the total amount of driving done in the metropolitan area. The existence of substantial levels of traffic congestion in Washington, as in other metro areas, strongly suggests that vehicle use is underpriced. To be sure, a constant VMT tax on all local mileage may not be the ideal instrument for correcting the congestion externality because congestion costs vary enormously with time of day and location, but it is simpler to implement than congestion pricing and may be a useful second-best policy in many situations.

Whereas LNYW attacks commuting inefficiency indirectly, by encouraging the reduction in motorists' principal daily destination, the VMT tax directly penalizes all driving, not just the journey to work. It is not immediately evident which policy should be the most effective and efficient as each policy clearly has both disadvantages and advantages over the other. Among the advantages of LNYW is its ease of implementation. Those who are eligible for and desire the subsidy identify themselves. In contrast, collection of the VMT tax in an efficient and nonintrusive manner is problematic, although recent advances in wireless data collection may alleviate these difficulties. On the other hand, the VMT tax directly incentivizes the reduced use of motor vehicles.

Just as in the case with LNYW policies, to avoid the possible complications of policy evaluation related to the redistribution of the revenue from tax collection, we do not recycle the proceeds back into the economy. Analogous to the LNYW case, the key indicator is the difference between the change in total welfare across all individuals and the total tax revenue. Only if the reduction in total welfare is exceeded by the VMT tax revenues does the policy generate a net efficiency gain. The only difference is that, whereas the subsidy causes the LNYW policy to look better than it actually is, the unrecycled tax revenues cause the VMT tax to look worse than it is.

\section{Results}

\section{Mean Outcomes}

\section{LNYW Results}

Table 4 and Figure 2 show the results of the three LNYW policies. The first three rows of the table give results for the Beltway policy at three different subsidy levels: $\$ 260, \$ 520$, and $\$ 780$ per year, which are the approximate annualized equivalents (at 5 percent for 30 years) of 
the three subsidy levels of $\$ 4000, \$ 8000$, and $\$ 12,000$. The key numbers in the table are in the columns for per capita subsidy and per capita welfare gain. Keep in mind, however, that the subsidy goes only to those agents who are eligible for and accept the offer and who change their place of residence or employment. Such agents are definitely net beneficiaries of the policy; otherwise, they would not accept the offer. On the other hand, their gain is in kind and not in cash, and may not be equal to the cash value. As for the remaining agents, they gain to the extent that the LNYW policies achieve smart growth objectives, such as reducing congestion and improving air quality. They may also gain — or lose — if their homes gain or lose value as a result of the relocations induced by the policy. They lose their share of the subsidy payment, which will be, on average, the amount shown in the table. Thus, the distributional outcomes are, in fact, quite skewed, with all benefits going to the lucky few, who may be relatively poor or rich, depending on the policy design. If others are to benefit, the public good aspects of the relocations must outweigh the costs of the subsidy.

As shown, all of the LNYW policies are inefficient. The LNYW all-zones policy is a much larger social program than the two Beltway policies, as indicated by the increase of at least five-fold in total subsidy at comparable subsidy levels. For the Beltway policy, we have three different subsidy levels, and the ratio of welfare gains to costs remains essentially constant regardless of the level. On the other hand, the ratio of the net welfare to the subsidy is about -15 percent for the Beltway policy, -19 percent for the Beltway12 policy, but only -9 percent for the LNYW all-zones policy. Thus, holding subsidy level constant, the ratio declines as the eligibility requirements are expanded.

Though in a general equilibrium setting it is difficult to disentangle the individual effects of economic and transportation factors, the welfare decomposition shown in equation (3) above allows us to estimate the effects of each of the key economic variables: wage income, nonwage income, retail prices, housing rents, commuting costs, and cost of other travel. For each variable, the decomposition shows the approximate contribution, positive or negative, to the observed change in welfare. That is, if we think of approximated welfare as a function of the variables across the top of the table (e.g., wage income and nonwage income), the entry in Tables 5a-c is the product of the change in the variable multiplied by the derivative of welfare with respect to that variable. The correction term is the difference between the sum of these terms in the Taylor series expansion and the value of the welfare function itself.

The welfare decomposition at the $\$ 520$ annual subsidy level is shown in Table 5. The main contributors to welfare for the two Beltway LNYW policies are the changes in wage and nonwage income (Table 5a and $5 \mathrm{~b}$ ), followed by changes in consumer prices and rent that 
slightly reduce welfare. Transportation costs hardly contribute anything to the welfare change. This same pattern holds also for the LNYW all-zones policy (Table 5c), with the exception of a 10 -fold increase in the magnitude of the effects. The all-zones policy affects a much larger population, so the subsidies are much larger. Recall that the entries in Table 5 do not reflect the subsidies themselves; once the subsidies are taken into account, the total welfare is negative.

Why are the LNYW policies inefficient? One plausible reason is that the relocation of agents into zones of higher density causes more traffic congestion than it relieves by reducing total VMT. As shown in Table 6, however, congestion costs barely change upon implementation of the Beltway policy (the other LNYW policies yield comparable results). In fact, traffic variables hardly change at all. Instead, the most likely explanation for LNYW inefficiency is that individual agents who are induced to relocate by the policy do not value the change as much as it costs. In the baseline, equilibrium prevails and no agent can be made better off by moving from one zone to another. Note that this applies at any subsidy level because the process starts from equilibrium, where all advantageous changes have already been made. Perhaps some agents are close to moving without the subsidy. Suppose an agent would experience a welfare loss of only $\$ 100$ per year to move into a zone favored by LNYW. Now the policy is imposed and that agent is offered $\$ 520$ per year to cover closing costs if he moves. This agent would enjoy a net welfare gain of $\$ 420$ per year, so naturally he accepts the subsidy and moves. However, the subsidy takes $\$ 520$ per year away from other agents in the region, so the net welfare loss is $\$ 100$. This is a common problem for subsidized consumption: the valuation of goods provided to beneficiaries inevitably lags behind the total costs required to produce or acquire those goods. In a benefitcost framework, the justification of such policies is that the additional consumption of the favored good has public good benefits to other parties that, together with the private benefits, exceed the cost. While that is a theoretically plausible outcome in this case, the results of the model suggest otherwise; that is, that the public good benefits fall short.

We observe above that the percentage net losses vary with the scope of the policyhighest for the Beltway12 policy and lowest for the all-zones policy. However, it turns out that this relationship is not causal; it is simply a correlation. So what does cause the pattern of observed losses to behave in this way? The ultimate reason is that, for any individual who takes advantage of the subsidy, the difference between the cost of provision of the good and the willingness to pay depends on skill class (i.e., income): the lower the income, the lower the willingness to pay. Thus, it is no surprise to find that the Beltway12 policy, which has the highest proportion of low-income workers (skill classes 1 and 2) among the total eligible (100 percent), 
also has the worst percentage net losses (19 percent), followed by the Beltway policy (63 percent eligible and 15 percent losses). The all-zones policy has 58 percent eligible and 9 percent losses.

Of course, sometimes policies are implemented precisely because they affect the distribution of welfare in a desirable way. Thus, a more complete evaluation of the Beltway policies must wait until their distributional effects are considered more explicitly.

\section{VMT Results}

Figure 3 and Table 7 show the results of simulating the VMT tax at different levels. As shown, net welfare is maximized at a tax rate of slightly more than $2 \phi$ per mile, which is the rate used in our policy comparison. This tax rate also yields the highest percentage net welfare gain, about 13 percent of the tax collected. The reason the VMT tax initially generates welfare benefits is that, by reducing driving, it reduces traffic congestion. But very high levels of the tax discourage driving too much, and the net welfare turns negative. For example, we can observe such an outcome at the tax level of $5 \not$ per mile.

Unlike the LNYW subsidy policies discussed above, the VMT tax increases the costs of all car trips, including commuting and shopping (Table 8), leading to substantial mode shifts that take cars off the road. The large increase in HOV use speaks to the relative paucity of transit alternatives outside of the downtown area and certain corridors into downtown, as well as the inadequacy of park-and-ride facilities in low-density areas inside the Beltway.

In terms of transportation impact, the VMT tax is a much more effective policy than is the LNYW. The average marginal costs of road congestion are reduced by 5.2 percent, and the total VMT is reduced by 7.7 percent (Table 8 ). The mode split of the trips is changing significantly, with the number of SOV trips decreasing by 10.2 percent and number of trips made by alternative modes increasing, most notably for HOV (15.4 percent) and nonmotorized trips (8.8 percent). Moreover, the VMT tax actually reduces the average commuting distance of the metro area residents by a little more than 1 percent; it reduces the average shopping trip by a little more than 0.25 percent. The VMT tax seems to reduce travel, including commuting trips, far better than the various policies ostensibly promoting proximity between work and home locations.

The welfare decomposition for the VMT tax policy (Table 9) shows outcomes that are roughly the opposite of the LNYW all-zones policy. These policies are at approximately the same scale, but whereas LNYW increases incomes (raising welfare) and raises prices and rents (reducing welfare), the VMT tax lowers income, prices, and rents. The exception is 
transportation costs, which are a major factor (adversely) affecting net welfare. On the other hand, a steep rise in driving costs leads to a substantial shift to public transit, generating substantial transit revenue. The redistribution of the transit revenue in this scenario is a substantial component of the nonwage income shown in Table 9.

The VMT tax on all trips reduces bids for housing in all zones of the metro area except for the very center. In the zones far away from the downtown area the rents are reduced relatively more. This effect attenuates, to some degree, the more commonly understood effect of transportation taxes; namely, the movement of both population and firms to more central locations. Although this policy does not explicitly promote living near one's work, in all zones the number of residents who both work and live in the same zone increases. Following rents, wages also decline over the entire urban area. It may seem strange that rents should decline, if the VMT tax is inducing agents to relocate to the center. The most likely explanation is that Table 9 reports average rents over the entire metro area. The fall in rents on the periphery, where households are leaving, more than offsets the increase in rents at the center. In any case, the fall in rents (and prices) is relatively small.

\section{Distributional Outcomes}

The results above on mean outcomes are interesting but perhaps not particularly surprising. The VMT tax is known to be more efficient in the present context than consumption subsidies such as LNYW programs; for example, see Safirova et al. (2007). If there is novelty in this paper, it lies in the distributional results, which follow. In this paper, we present three ways of looking at the distribution of changes in net welfare in the four scenarios:

- average deviations from the overall mean by skill class,

- distribution functions of outcomes by skill class, and

- regional maps indicating zones of particularly favorable or unfavorable outcomes by skill class.

\section{Average Deviations}

Average gains or losses by income group is probably the most common way of displaying distributional results. For each of the four policy scenarios, column 1 of Table 10 gives the mean net welfare change. In this instance, we see similar patterns for the three LNYW policies. For each, skill classes 1 and 4 enjoy above average net gains, and skill classes 2 and 3 reap below average gains. For the Beltway and all-zones policies, we also see that skill class 4 
enjoys benefits far above the others, while the benefits for skill class 2 are far below. (Generally speaking, skill class 2 individuals fare worst under the LNYW policies because their incomes are too high to be eligible to share in the revenues distributed back to the lowest income group, but not high enough to take advantage of the subsidy). Skill classes 1 and 4 gain benefits via two different mechanisms. With the highest incomes, level 4 households are in the best position to invest in housing, so they receive an inordinate share of the subsidy gains. For the all-zones policy, skill class 1 benefits because that LNYW policy promotes real estate activity and generates government revenue from real estate taxes, which are automatically redistributed within the model. These payments favor the lowest skill class. For the Beltway policy, the lowest income group is also favored because the increased real estate activity occurs within the Beltway, where a higher proportion of the lowest skill class lives. The Beltway12 policy, which is designed in part to improve distributional outcomes by limiting eligibility to skill classes 1 and 2, also favors skill classes 1 and 4 over skill classes 2 and 3, except in this case the overall winner is skill class 1 and the overall loser, skill class 3 . Thus, the Beltway 12 policy has slightly more progressive distributional characteristics than the other LNYW policies, but the scale of the policy is so small that the deviations are never far from the average. Indeed, the "all-zones" policy is the only LNYW policy for which the mean differs substantially among skill classes: $\$ 155$ per year from skill class 4 to skill class 2 .

The distribution by skill class for the $2 \varnothing$ VMT tax is completely different. Welfare gains by skill class follow numerical order from skill class 1 to skill class 4 . Gains for sSkill classes 1 and 2 are almost identical, and skill class 4 has by far the lowest net welfare gain. The spread in net welfare changes is considerably smaller than for the LNYW all-zones policy (the only LNYW policy of comparable scale), but the net welfare gains are much more favorable to lowerincome groups. The principal reason for the progressive distributional outcome is that the individuals in the highest skill class tend to live further from the center of the metro area, rely on motor vehicles much more, and have generally longer journey-to-work trips.

\section{Distribution Functions}

The distributional information in Tables 5 and 8, specifically the average welfare change for each of the four skill classes or income classes, is the most common kind of distributional information typically found in policy analyses. However, the fine detail that LUSTRE offers allows us to look not only at average outcomes by skill class, but how outcomes vary among agents for the same skill class. Figures $4 \mathrm{a}-\mathrm{d}$ show the distribution of average welfare gain in each of the interior zones of the model, for each skill class and for each policy scenario. 


\section{Beltway Policies (Figure $4 a$ and $4 b$ )}

Approximately 29 percent of the population of the region lives inside the Beltway. Thus, in considering the Beltway (Figure 4a) or the Beltway12 (Figure 4b) policies, one thing we look for is a break in the cumulative distribution function (cdf) at approximately the 30 percent or 70 percent probability level. In the Beltway policy, we don't really see such a break for skill classes 1 and 2; their cdfs are nearly straight lines, indicating a nearly uniform distribution. In the upper skill classes, we see what appears to be a modest break between 60 percent and 70 percent for skill class 3 and a much more prominent break for skill class 4 . Indeed, approximately a third of agents in skill class 4 enjoy strongly higher net welfare gains than the rest of skill class 4 or any of the lower skill classes. This looks a bit as though the Beltway policy somehow favors skill class 4 residents inside the Beltway. As it turns out, however, the skill class 4 residents favored by this policy live outside the Beltway, in parts of suburban Maryland, and the result is perhaps an incidental outcome of the baseline distribution of households. This can be seen in the lower right panel of Figure 5a.

In the Beltway12 policy, by contrast, the outcomes line up better with expectations. We see breaks at 30 percent probability for skill classes 3 and 4 , with the upper 70 percent enjoying a roughly constant gain and the rest suffering losses even before considering the required adjustments to ensure revenue neutrality. For skill classes 1 and 2, we see a break at about 70 percent, with that 70 percent experiencing a low and almost constant net welfare change. The remaining 30 percent enjoy much higher benefits that continue to increase in value. It seems clear that living within the Beltway favors the lower skill classes and punishes the upper skill classes.

The all-zones policy (Figure 4c) is fairly straightforward, favoring skill classes 1 and 4 and punishing 2 and 3, especially 2 . In this case, the distribution of the outcome depends much more on skill class than on the residential zone.

The VMT tax policy(Figure 4d) is more or less the reverse. It favors the two lower skill classes, whose cdfs are almost superimposed. Skill class 3 trails by some $\$ 40$ per agent, and skill class 4 trails 3 by a similar amount. Again, skill class matters more than location. This is a somewhat surprising result: one would think that location would matter more, inasmuch as agents in peripheral zones generally have to travel more to reach work and shopping. That turns out to be true, but the average welfare difference, due to the VMT tax, between those living inside and outside the Beltway is only $\$ 10$ to $\$ 17$ per year. This is a very important result in that it shows not only that a point estimate of individual cost is potentially highly misleading for 
many actual individuals, but that a distributional characterization of cost that does not stratify by the most important covariate can be only slightly less misleading. Here, an analysis that averages together the four parts of Figure 5d (in other words, a geographical analysis of variation in cost) would give citizens in sSkill classes 1 and 2 a jaundiced view of a policy that provides them with relatively higher net benefits, regardless of their location, than would be apparent.

\section{Regional Maps}

As shown in Table 4, the three LNYW policies are inefficient, yet for each, the per capita subsidy and per capita welfare gain are close to each other, so the average net welfare losses are only about 10 percent of either, around $\$ 2$ or $\$ 3$ for the two Beltway policies and around $\$ 10$ for the all-zone policy. Similarly, the VMT tax net welfare gain is only a small fraction of the net welfare change or the net per capita tax (Table 7), and is again around \$10. Yet across skill groups and residential zones, the benefit outcomes are much larger than this, and for purposes of looking at winners and losers, the average net change in welfare can be ignored as it is overwhelmed by the variation in outcomes. Figures $5 \mathrm{a}-\mathrm{d}$ show the net welfare gains by zone for the four policies under discussion. The way to read these maps is as follows. First, the benefit range at the top of the figure is the difference between the maximum and minimum net welfare gain among the four skill classes and 36 zones. The zones are shaded according to their net welfare gains as a percentage of the benefit range. Thus, we see that for the Beltway policy (Figure 5a), the benefits to virtually all skill class 1 and skill class 2 agents lie in the 0-15 percent range, or a net welfare gain of about $\$ 0-\$ 11.50$. Skill class 3 hardly does any better. Most of the benefits go to skill class 4, whose gains throughout the region lie mostly in the 3070 percent range, although some level 4 residents in Montgomery and Prince George's Counties are in the top bin.

For the Beltway12 policy (Figure 5b) the story is decisively different, though the range remains about the same. Now the biggest gains go to skill classes 1 and 2, which enjoy benefits above 70 percent of the range. The gains are particularly strong within the Beltway. In skill classes 3 and 4, most zones still enjoy benefits of 30 percent or better. Only a small number of zones have benefits in the lowest bin, and they are concentrated in Southeast and Northeast DC and western Prince George's County, as shown in the fourth panel of Figure 5b.

The benefits map for the all-zones policy (Figure 5c) reinforces the interpretation of the distribution function discussion above: variation in outcome depends more on skill class than it does on location. 
The same is true for the VMT tax (Figure 5d), except the order is roughly reversed from that of the all-zones LNYW. Of the four policies, only the VMT tax can boast positive net benefits. It is also the only policy that has progressive distributional properties. Nonetheless, one should keep in mind that VMT taxes are not optimal, and that even greater gains could be realized by policies that replace a flat per-mile fee by a fee that is sensitive to location and time of day or week.

\section{Conclusions}

In this paper, we use a detailed regional CGE model to compare the outcomes of four local antisprawl policies, including three variants of LNYW policies, and one VMT tax. Such LNYW programs currently exist in a number of states and operate at different geographic scales (from municipal to state levels). We find that all versions of the LNYW programs are inefficient and are likely to become even less efficient when our uniform simplifying assumptions about program financing are relaxed. What is even more discouraging is that the transportation impact of the programs is also very moderate. Contrary to the vision of smart growth supporters, our results suggest that an LNYW program that operates only in a central "priority area" does not make many residents change their mode of transportation or reduce the length of auto trips. Furthermore, when the program is adopted all over the metro area, the program becomes slightly more efficient economically but is even less effective as a centralizing force in the metro area.

On the other hand, an alternative policy, a VMT tax (evaluated at its optimal level), is efficient and has a much bigger transportation impact. Moreover, if the no-recycling assumption is relaxed, it would become even more efficient. However, there is nothing new in finding an efficiency advantage of policies that actively penalize driving (such as the VMT tax) compared to policies that encourage relocation to reduce the journey to work. Of more interest is the difference in distributional outcomes and, in particular, the overall finding that the VMT tax has a more progressive distributional profile than the LNYW policies. After all, one of the justifications of the latter is fairness, yet the features of those policies that promote fairness (such as restriction of eligibility to lower-income groups) reduce efficiency with only a modest improvement in distributional features. Such restrictions also reduce effectiveness because so few of those eligible to participate are actually in a position to do so. We have seen that the differences in outcomes vary substantially by policy details and, for each policy, by income level and location. Note that the observed variation is probably an underestimate of the degree of variation that would be observed in actual policy implementation. The reason is that the outcomes and data do not differentiate among agents except by residence zone and income. But 
within a zone and a skill class, the impact of the policies will be very different because of varied work destinations, shopping destinations, and mode choices, among other things. A useful extension of this research would be to disaggregate model outcomes more extensively than we have been able to do in this project.

We conclude with a few reflections about the issues involved in predicting distributional outcomes of other types of regulation and, in particular, of federal health and safety regulation. The distribution of costs and benefits is supposed to be an important consideration of such regulations, as attested by the repeated issuance of executive orders requiring distributional analysis of regulatory benefits and costs. Actual compliance with this requirement has been fitful, with occasional benefit assessments made with respect to certain vulnerable populations. Distributional analyses of costs have tended to be restricted to the effects on firms, regions, towns, or other collectives that are subject to these regulations. To produce analyses that trace outcomes down to the level of individuals, behavioral models will be needed that can link impacts on these collectives to their members, employees, customers, and the like. At present, these distributional considerations have been restricted to a limited subset of regulations, such as Safe Drinking Water Act rules that may impose particularly burdensome rules on water supply with only a small number of subscribers, or industrial air or water pollution rules that use simple aggregate models to estimate impacts on plant closures, unemployment, or prices. Such models can be useful, but still, even these outcomes can have very disparate welfare impacts on the individuals that suffer them. In short, the development of disaggregated behavioral models, such as those employed in this project, is likely to be complicated. But once these models are available, they will be quite useful to understanding the consequences of such regulations. 


\section{References}

Anas, A., and R. Xu. 1999. Congestion, Land Use and Job Dispersion: A General Equilibrium Model. Journal of Urban Economics 45: 451-473.

Arnott, R. 2007. Congestion Tolling with Agglomeration Externalities. Journal of Urban Economics 62(2): 187-203.

Brueckner, J. 2000. Urban Sprawl: Diagnosis and Remedies. International Regional Science Review 23: 160-179.

Brueckner, J. 2001. Urban Sprawl: Lessons from Urban Economics. Brookings-Wharton Papers on Urban Affairs 65-89.

Coglianese, C., A.M. Finkel, and C. Carrigan (eds.). 2013. Does Regulation Kill Jobs?

Philadelphia, PA: University of Pennsylvania Press (forthcoming).

Cranor, C., and A.M. Finkel. 2013. Towards Recognizing Individual Benefits and Costs in CostBenefit Analysis. Manuscript in review.

Croombe, D.P., G. Scholefield, and A. Skinner. 1997. Study of Parking and Traffic Demand Part 3: The Effects of Parking Control Strategies in Bristol. Traffic Engineering and Control 38(4): 204-208.

Finkel, A.M. 2013. The Cost of Nothing Trumps the Value of Everything: The Failure of Regulatory Economics To Keep Pace with Improvements in Quantitative Risk Analysis. Manuscript in review.

May, A.D., M. Roberts, and P. Mason. 1992. The Development of Transport Strategies for Edinburgh. Proceedings of the Institution of Civil Engineers: Transportation 95: 51-59.

Metropolitan Washington Council of Governments. 1999. Version 1 Transportation Model.

Nelson, P., A. Baglino, W. Harrington, E. Safirova, and D.A. Lipman. 2007. Transit in Washington, DC: Current Benefits and Optimal Level of Provision. Journal of Urban Economics 62(2): 231-251.

Nelson, P., K. Gillingham, and E. Safirova. 2003. Revving up the Tax Engine: Gas Taxes and the DC Metro Area's Transportation Dilemma. Issue Brief 03-05. Washington, DC: Resources for the Future. 
Parry, I.W.H., and A. Bento. 2001. Revenue Recycling and the Welfare Effects of Road Pricing. Scandinavian Journal of Economics 103: 645-671.

Safirova, Elena, 2002. "Telecommuting, Traffic Congestion and Agglomeration: A General Equilibrium Model," Journal of Urban Economics, 52: pp. 26-52.

Safirova, E., K. Gillingham, W. Harrington, and P. Nelson. 2003. Are HOT Lanes a Hot Deal? The Potential Consequences of Converting HOV to HOT Lanes in Northern Virginia. Issue Brief 03-03. Washington, DC: Resources for the Future.

Safirova, E., K. Gillingham, W. Harrington, P. Nelson, and D. Lipman. 2005. Choosing Congestion Pricing Policy: Cordon Tolls vs. Link-Based Tolls. Transportation Research Record 1932:169-177.

Safirova, E., K. Gillingham, and S. Houde. 2007. Measuring Marginal Congestion Costs of Urban Transportation: Do Networks Matter? Transportation Research Part A 41(8): 734749.

Safirova, E., W. Harrington, P. Nelson, I.W. Parry, K. Gillingham, and D. Mason. 2004. Welfare and Distributional Effects of Road Pricing Schemes for Metropolitan Washington, DC. In Road Pricing: Theory and Evidence, edited by G. Santos. Amsterdam: Elsevier Science, 179-206.

Safirova, E., S. Houde, D. Lipman, W. Harrington, and A. Baglino. 2006. Congestion Pricing: Long-Term Economic and Land Use Effects. Discussion paper 06-37. Washington, DC: Resources for the Future. 


\section{Mathematical Appendices}

\section{A. LUSTRE (CGE Model)}

\section{RELU}

In what follows, we briefly describe the mathematical structure of RELU. Table A1 lists all variables and parameters of RELU.

\section{Consumers/Workers}

Consumers in RELU are exogenously distributed into F skill groups. While they cannot change their skill group, each consumer within a skill group can make a series of choices. After deciding whether to work or to remain unemployed, consumers choose a triple $(i, j, k)$ corresponding to the choices of where to reside, where to work, and what type of housing to choose. ${ }^{3}$ Discrete choice decision-making is characterized with a nested multinomial logit. Conditional on discrete choices, consumers decide how much housing to rent, the quantity of retail goods to purchase at each available retail location, and how much labor to supply. ${ }^{4}$

We assume that the utility function of consumers is Cobb-Douglas between housing and aggregate consumption, while the subutility of all retail goods is CES. Then, the Marshallian consumer demands for retail goods and housing (for employed and unemployed consumers, respectively) take the form:

$$
\begin{aligned}
& Z_{z \mid i j f}=\frac{l_{z \mid i j f}^{\frac{1}{1-\eta_{f}}} \psi_{z \mid l i j}^{\frac{1}{\eta_{f}-1}}}{\sum_{s} \frac{1}{l_{s i j f}} \psi_{s}^{\frac{\eta_{f}}{\eta_{f-1}}}} \alpha_{f} \Psi_{i j f} \\
& Z_{z \mid i f}^{u}=\frac{\frac{1}{l_{z \mid i f}^{1-\eta_{f}}} \psi_{z \mid i}^{\frac{1}{\eta_{f}-1}}}{\sum_{s} l_{s \mid i f}^{\frac{1}{1-\eta_{f}}} \psi_{s \mid i}^{\frac{\eta_{f}}{\eta_{f-1}}}} \alpha_{f} M_{f}
\end{aligned}
$$

\footnotetext{
3 Unemployed consumers choose a pair (i,k).

${ }^{4}$ Although in the model we do not have leisure, aggregate labor supply is elastic because of unemployment and variation in time spent traveling to shop.
} 


$$
\begin{aligned}
& b_{i j k \mid f}=\beta_{f} \frac{\Psi_{i j f}}{R_{i k}} \\
& b_{i k \mid f}^{u}=\beta_{f} \frac{M_{f}}{R_{i k}},
\end{aligned}
$$

where $\Psi$ is full consumer income (net of taxes and commuting costs), $M$ is the unearned income component, $\psi$ is the full price of a consumer good, and each $\mathrm{l}$ is a coefficient reflecting the intrinsic attractiveness of a shopping location. The net full incomes and full prices of retail goods faced by the employed and unemployed are given in equations (A3) and (A4) below.

$$
\begin{gathered}
\Psi_{i j f}=\left(1-\vartheta_{f}\right) w_{j f}\left(H_{f}-d G_{i j f}^{w}-d G_{j i f}^{w}\right)+\left(1-\vartheta_{f}\right) M_{f}-d g_{i j f}^{w}-d g_{j i f}^{w} \\
\Psi_{i j f}^{u}=\left(1-\vartheta_{f}^{u}\right) M_{f} \\
\psi_{z \mid i j f}=p_{\Re z}+\left[g_{z i f}^{n w}+g_{i z f}^{n w}+\left(1-\vartheta_{f}\right) w_{j f}\left(G_{i z f}^{n w}+G_{z i f}^{n w}\right)\right] c_{i j f} \\
\psi_{z i j f}^{u}=p_{\Re z}+\left[g_{z i f}^{n w}+g_{i z f}^{n w}\right] c_{i f}^{u}
\end{gathered}
$$

In equations (A3-A4), $g$ and $G$ stand for one-way time and monetary transportation costs, respectively; $\vartheta$ is the income tax rate; and $\mathrm{c}$ is a coefficient reflecting the number of shopping trips required to purchase one unit of a good.

The portions of indirect utility functions common to all consumers but dichotomized by work status ( $\mathrm{w}=E$ for employed or $w=U$ for unemployed) are:

$$
\begin{aligned}
& \tilde{U}_{i j k \mid f, w=E}=\alpha_{f} \ln \alpha_{f}+\beta_{f} \ln \beta_{f}+\ln \Psi_{i j f}-\beta_{f} \ln R_{i k}-\frac{\alpha_{f}\left(\eta_{f}-1\right)}{\eta_{f}} \ln \left(\sum_{z} \frac{1}{l_{z \mid i j f}^{1-\eta_{f}}} \psi_{z \mid i j f}^{\frac{\eta_{f}}{\eta_{f}-1}}\right)+E_{i j k \mid f, w=E}^{L} \\
& \tilde{U}_{i k \mid f, w=U}^{u}=\alpha_{f} \ln \alpha_{f}+\beta_{f} \ln \beta_{f}+\ln M_{f}-\beta_{f} \ln R_{i k}-\frac{\alpha_{f}\left(\eta_{f}-1\right)}{\eta_{f}} \ln \left(\sum_{z} \frac{1}{1-\eta_{f i f}} \psi_{z \mid i f}^{\frac{\eta_{f}}{\eta_{f}-1}}\right)+E_{i k \mid f, w=U}^{L},
\end{aligned}
$$

where coefficients $E_{i j k \mid f w}^{L}$ measure the intrinsic attractiveness of $(i, j, k)$ bundles. Assuming that idiosyncratic utilities in this model are $\sim$ i.i.d. Gumbel with dispersion parameter $\lambda_{f w}^{L}$, we arrive at multinomial logit probabilities of consumer choices for the lower nest of the nested logit: 


$$
\begin{aligned}
& P_{i j k \mid f, w=E}^{L}=\frac{\exp \left(\lambda_{f, w=E}^{L} \tilde{U}_{i j k \mid f, w=E}\right)}{\sum_{s=1 \ldots \Im ; m=1 \ldots \Im ; n=1 \ldots K_{1}} \exp \left(\lambda_{f, w=E}^{L} \tilde{U}_{s m n \mid f, w=E}\right)+\sum_{s=1 \ldots \Im ; n=1 \ldots K_{1}} \exp \left(\lambda_{f, w=U}^{L} \tilde{U}_{s n \mid f, w=U}\right)} \\
& P_{j k \mid f, w=U}^{L}=\frac{\exp \left(\lambda_{f, w=U}^{L} \tilde{U}_{i j k \mid f, w=U}\right)}{\sum_{s=1 \ldots \Im ; m=1 \ldots \Im ; n=1 \ldots K_{1}} \exp \left(\lambda_{f, w=E}^{L} \tilde{U}_{s m n \mid f, w=E}\right)+\sum_{s=1 \ldots \Im ; n=1 \ldots K_{1}} \exp \left(\lambda_{f, w=U}^{L} \tilde{U}_{s n \mid f, w=U}\right)}
\end{aligned}
$$

At the higher nest, the choice of work status is based on the composite utility from the choice bundle at the lower nest. The composite utility is given by:

$$
V_{w \mid f}=E_{w \mid f}^{H}+\frac{1}{\lambda_{f w}^{L}} \ln \sum_{i j k} e^{\lambda_{f w}^{L} \tilde{U}_{i j k \mid f w}}
$$

Similarly, coefficients $E_{w \mid f}^{H}$ measure the intrinsic attractiveness of each work status choice and, assuming that idiosyncratic utilities in this model are $\sim$ i.i.d. Gumbel with dispersion parameter $\lambda_{f}^{H}$, we arrive at multinomial logit probabilities for the higher nest:

$$
\begin{gathered}
P_{w=E \mid f}^{H}=\frac{\exp \left(\lambda_{f}^{H} V_{w=E \mid f}\right)}{\sum_{w=E, U} \exp \left(\lambda_{f}^{H} V_{w \mid f}\right)} \\
P_{w=U \mid f}^{H}=\frac{\exp \left(\lambda_{f}^{H} V_{w=U \mid f}\right)}{\sum_{w=E, U} \exp \left(\lambda_{f}^{H} V_{w \mid f}\right)}
\end{gathered}
$$

The probability choices model for the whole nested multinomial logit is then given by

$$
P_{i j k w \mid f}=P_{w \mid f}^{H} P_{i j k \mid f w}^{L}
$$

Equation (A7) shows the components of unearned income-income from capital, income from real estate, and income inflow from outside of the region.

$$
M_{f}=\frac{\xi_{f}}{N_{f}}\left[\left(\frac{\rho}{1+\rho} \sum_{r} \sum_{j} K_{r j}\right)+\sum_{k} \sum_{j} \frac{\rho-\tau_{j k}}{1+\rho} V_{j k} S_{j k}+\Theta\right]
$$

\section{Producers}

The producers in the model are perfectly competitive profit maximizers, with a CobbDouglas production function between four large groups of inputs_-labor, capital, buildings, and intermediate inputs. At the same time, within input groups (by analogy with consumers), inputs 
feature constant elasticity of substitution. The input demands for labor, buildings, capital, and intermediate inputs are shown in equations (A10)-(A13), where

$\kappa, \chi$, and $\mathrm{v}$ are coefficients reflecting the intrinsic attractiveness of particular labor, building, and intermediate inputs.

$$
\begin{aligned}
& L_{f \mid r j}=\frac{\kappa_{f \mid r j}^{\frac{1}{1-\theta_{r}}} w_{j f}^{\frac{1}{\theta_{r}-1}}}{\sum_{z=0 \ldots F} \kappa_{z \mid r j}^{\frac{1}{1-\theta_{r}}} w_{j z}^{\frac{\theta_{r}}{\theta_{r-1}}}} \delta_{r} p_{r j} X_{r j} \\
& B_{k \mid r j}=\frac{\chi_{k \mid r j}^{\frac{1}{1-\zeta_{r}}} R_{j k}^{\frac{1}{\zeta_{r}-1}}}{\sum_{z=0, K_{1} \ldots K} \chi_{z \mid r j}^{\frac{1}{1-\zeta_{r}}} R_{j z}^{\frac{\zeta_{r}}{\zeta_{r-1}}}} \mu_{r} p_{r j} X_{r j} \\
& K_{r j}=v_{r} \frac{p_{r j} X_{r j}}{\rho} \\
& Y_{s n \mid r j}=\frac{v_{s n \mid r j}^{\frac{1}{1-\varepsilon_{r}}} \hat{p}_{s n \mid r j}^{\frac{1}{\varepsilon_{r}-1}}}{\sum_{n=1 \ldots \Im} v_{s n \mid r j}^{\frac{1}{1-\varepsilon_{r}}} \hat{p}_{s n \mid r j}^{\frac{\varepsilon_{r}}{\varepsilon_{r}-1}}} \gamma_{s r} p_{r j} X_{r j}
\end{aligned}
$$

In equation (A13), $\hat{p}$ denotes the full price of the intermediate input inclusive of freight costs.

\section{Landlords}

The model of landlord behavior helps to explain the short-run supply of floor space in buildings. Assuming that idiosyncratic portions of building maintenance costs are i.i.d. Gumbel with a dispersion parameter $\varphi$, and that costs common to all landlords are denoted by $D$, equation (A14) shows the probability that a landlord would decide to rent out one unit of floor space. 


$$
\begin{gathered}
q_{i k}=\frac{\exp \left[\phi_{i k}\left(R_{i k}-D_{i k o}\right)\right]}{\exp \left[\phi_{i k}\left(R_{i k}-D_{i k o}\right)\right]+\exp \left[\phi_{i k}\left(-D_{i k v}\right)\right]} \\
\omega_{i k}=\frac{1}{\phi_{i k}} \ln \left(\exp \left[\phi_{i k}\left(R_{i k t}-D_{i k o}\right)\right]+\exp \left[\phi_{i k}\left(-D_{i k v}\right)\right]\right)
\end{gathered}
$$

\section{Developers}

By analogy with the landlord model, the model of developers describes optimal rules of constructing and demolishing buildings. Assuming that idiosyncratic costs related to construction and demolition are i.i.d. Gumbel with dispersion coefficient $\Phi$, equation (A16) shows the probability that a profit-maximizing developer will decide to construct a new property on a unit of land, while equation (A15) computes the probability that a unit of building will be demolished. ${ }^{5}$

$$
\begin{aligned}
& Q_{i 0 k}\left(\bar{V}_{i}\right)=\frac{\exp \left[\frac{1}{1+\rho} \Phi_{i 0}\left(V_{i k}-p_{(\Re+k) i}\right) m_{i k 0}+F_{i 0 k}\right]}{\exp \left[\frac{1}{1+\rho} \Phi_{i 0} V_{i 0}+F_{i 00}\right]+\sum_{l \in \Omega_{i 0}^{C}} \exp \left[\frac{1}{1+\rho} \Phi_{i 0}\left(V_{i l}-p_{(\Re+l) i}\right) m_{i k 0}+F_{i 0 l}\right]} \\
& Q_{i k 0}\left(\bar{V}_{i}\right)=\frac{\exp \left[\frac{1}{1+\rho} \Phi_{i k}\left(V_{i 0} \frac{1}{m_{i k 0}}-p_{(\Re+\aleph+k) i}\right)+F_{i k 0}\right]}{\exp \left[\frac{1}{1+\rho} \Phi_{i k}\left(V_{i 0} \frac{1}{m_{i k 0}}-p_{(\Re+\aleph+k) i}\right)+F_{i k 0}\right]+\exp \left[\frac{1}{1+\rho} \Phi_{i k}\left(V_{i k}\right)+F_{i k k}\right]}
\end{aligned}
$$

\section{General Equilibrium}

General equilibrium is formed by seven sets of conditions.

1. Zero profit condition

\footnotetext{
5 Here we present a static, stationary version of the model.
} 


$$
\begin{aligned}
p_{r j}=A_{r j}^{-1} \rho^{v_{r}} & \delta_{r}^{-\delta_{r}} \mu_{r}^{-\mu_{r}} v_{r}^{-v_{r}}\left(\prod_{s} \gamma_{s r}^{-\gamma_{s r}}\right)\left(\sum_{f=0 \ldots F} \kappa_{f \mid r j}^{\frac{1}{1-\theta_{r}}} w_{j f}^{\frac{\theta_{r}}{\theta_{r}-1}}\right)^{\frac{\delta_{r}\left(\theta_{r}-1\right)}{\theta_{r}}} \\
& \times\left(\sum_{k=0 \ldots K+1} \chi_{k \mid r j}^{\frac{1}{1-\zeta_{r}}} R_{j k}^{\frac{\zeta_{r}}{\zeta_{r}-1}}\right)^{\frac{\mu_{r}\left(\zeta_{r}-1\right)}{\zeta_{r}}} \times \prod_{s=1 \ldots 12}\left(\sum_{n=1, \ldots, \mathcal{J}} v_{s n \mid r j}^{\frac{1}{1-\varepsilon_{r}}} \hat{p}_{s n \mid r j}^{\frac{\varepsilon_{r}}{\varepsilon_{r}-1}}\right)^{\frac{\gamma_{s r}\left(\varepsilon_{r}-1\right)}{\varepsilon_{r}}}
\end{aligned}
$$

2. Labor market clearing

$$
\sum_{r=1, \ldots, 12} L_{f \mid r j}=\sum_{i=1 \ldots \Im, k=1,2}\left(H-d G_{i j}^{w}-d G_{j i}^{w}-\sum_{z \in \Omega_{i}^{n n}} c_{i j f} Z_{z \mid i j f}\left(G_{i z}^{n w}+G_{z i}^{n w}\right)\right) N_{f} P_{i j k \mid f}
$$

3. Residential floor space clearing

$$
\sum_{f=1 \ldots F} N_{f}\left(\sum_{j} P_{i j k \mid f} b_{i j k \mid f}+P_{i k \mid f}^{u} b_{i k \mid f}^{u}\right)=S_{i k} q_{i k}
$$

4. Business floor space and agricultural land clearing

$$
\sum_{r} B_{j k \mid r}=S_{j k} q_{j k}
$$

5. Goods market clearing

$$
\begin{aligned}
& \sum_{n=1 \ldots 2 K+R} \sum_{s=0,1 \ldots \Im} Y_{r i \mid n s}+\Xi_{r i}=X_{r i} ; r=1,2,3 . \\
& \sum_{f=1 \ldots F} N_{f}\left(\sum_{n=1 \ldots \Im, s=1 \ldots \Im ; k=1, K_{1}} P_{n s k \mid f} Z_{i \mid n s k}+\sum_{n k} P_{n k \mid f}^{u} Z_{i \mid n k}^{u}\right)+\Xi_{\mathfrak{R} i}=X_{\mathfrak{R} i}
\end{aligned}
$$

6. Asset valuation

For $k=0$

$$
\frac{1+\rho+\tau_{i k}}{1+\rho} V_{i 0}=\omega_{i 0}\left(R_{i 0}\right)+\frac{1}{\Phi_{i 0}} \ln \left\{\begin{array}{l}
\exp \left(\frac{1}{1+\rho} \Phi_{i 0} V_{i 0}+F_{i 00}\right)+ \\
\sum_{l \in \Omega_{i 0}^{C}} \exp \left[\frac{1}{1+\rho} \Phi_{i 0}\left(V_{i l}-p_{(\Re+l) i}\right) m_{i l 0}+F_{i 0 l}\right]
\end{array}\right\},
$$


For $k>0 \frac{1+\rho+\tau_{i k}}{1+\rho} V_{i k}=\omega_{i k}\left(R_{i k}\right)+\frac{1}{\Phi_{i k}} \ln \left\{\begin{array}{l}\exp \left(\frac{1}{1+\rho} \Phi_{i k} V_{i k}+F_{i k k}\right)+ \\ \exp \left[\frac{1}{1+\rho} \Phi_{i k}\left(V_{i 0} \frac{1}{m_{i k 0}}-p_{(\Re+\aleph+k) i}\right)+F_{i k 0}\right]\end{array}\right\}$, (A24b)

7. Stock adjustment

For $k>0: \quad S_{i k} Q_{i k 0}=m_{i k 0} S_{i 0} Q_{i 0 k}$

For $k=0: \quad \sum_{k=0, \ldots, \aleph} \frac{1}{m_{i k 0}} S_{i k}=J_{i}$.

\section{B. Welfare Decomposition}

Wage

$\sum_{j} \Delta w_{j \mid f} \frac{\partial W}{\partial w_{j \mid f}}=P_{w=E \mid f}^{H} \sum_{i j k} \frac{P_{i j k \mid f, w=E}^{L}\left(1-\vartheta_{f}\right)}{\Psi_{i j f}}\left(\frac{H_{f}-250 G_{i j}{ }^{\text {working }}}{60}-c_{i j f} \sum_{z} Z_{z \mid i j f} G_{i z}^{\text {shopping }}\right) \Delta w_{i}$

$W$ : Total welfare

Toll revenue distributed

$\Delta T R D_{f} \frac{\partial W}{\partial M_{f}}=\sum_{w} P_{w \mid f}^{H} \Delta T R D_{f} \sum_{i j k} \frac{P_{i j k \mid f w}^{L}\left(1-\vartheta_{f}\right)}{\Psi_{i j f}}$

where

$\triangle T R D:$ Toll revenue and additional transit fares collected and redistributed as a lump sum

Dividend

$$
\Delta D I V_{f} \frac{\partial W}{\partial D I V_{f}}=\sum_{w} P_{w \mid f}^{H} \Delta D I V_{f} \sum_{i j k} \frac{P_{i j k \mid f w}^{L}\left(1-\vartheta_{f}\right)}{\Psi_{i j f}}
$$

where

$\triangle D I V$ : Change in dividends 
Price

$$
\sum_{i j z} \Delta p_{\Re z \mid f} \frac{\partial W}{\partial p_{\Re z \mid f}}=-\sum_{w} P_{w \mid f}^{H} \sum_{i j k} \frac{P_{i j k \mid f w}^{L}\left(1-\vartheta_{f}\right)}{\Psi_{i j f}}\left(\sum_{z} Z_{z \mid i j f} \Delta p_{i j z}\right)
$$

where

$$
\Delta p_{\Re z}: \text { Change in retail prices }
$$

Rent

$$
\sum_{i k} \Delta R_{i k} \frac{\partial W}{\partial R_{i k}}=-\beta \sum_{w} P_{w \mid f}^{H} \sum_{i j k} \frac{P_{i j k \mid f w}^{L}}{R_{i k}} \Delta R_{i k}
$$

where

$\Delta R:$ Change in rents

Monetary costs of traveling to work

$$
\sum_{i j} \Delta G_{i j \mid f}^{w o r k i n g} \frac{\partial W}{\partial G_{i j \mid f}^{w o r k i n g}}=-250 P_{f \mid w=E}^{H} \sum_{i j k} \frac{P_{i j k \mid f w=E}^{L}}{\Psi_{i j f}} \Delta G_{i j}^{w o r k i n g}
$$

where

$\Delta G^{\text {working }}$ : Change in cost of commuting trips, with time elements converted in monetary units, weighted by the numbers of trips made in the reference versus the simulation

\section{Monetary costs of traveling to shop}

- $\sum_{i z} G_{i z \mid f}^{\text {shopping }} \frac{\partial W}{\partial G_{i z \mid f}^{\text {shopping }}}=-P_{w=E \mid f}^{H} \sum_{i j k} \frac{P_{i j k \mid f w=E}^{L}}{\Psi_{i j f}} c_{i j f} \sum_{Z} Z_{z \mid i j f} \Delta G_{i z}^{\text {shopping }}-P_{w=U \mid f}^{H} \sum_{i j k} \frac{P_{i j k \mid f w=U}^{L}}{M_{f}} c_{i j f} \sum_{Z} Z_{z \mid i j f} \Delta G_{i z}^{\text {shopping }}$

where

$\Delta G^{\text {shopping }}$ : Change in cost of shopping trips, with time elements converted in monetary units, weighted by the numbers of trips made in the reference versus the simulation. 
Table A1. Variables and Parameters of RELU

\begin{tabular}{|c|c|c|}
\hline Indices & Description & Dimension \\
\hline$i$ & Residence place & 40 \\
\hline$j$ & Work place (Production place) & 40 \\
\hline$z$ & Retail location & 40 \\
\hline$k$ & Housing type & $\begin{array}{l}2 \text {, single unit and } \\
\text { multiunit familial } \\
\text { housing }\end{array}$ \\
\hline$b$ & Building type & $\begin{array}{l}\text { 2, commercial and } \\
\text { industrial }\end{array}$ \\
\hline$f$ & Consumer type (skill) & 4 \\
\hline$w$ & Work Status & $\begin{array}{l}2, \text { employed and } \\
\text { unemployed }\end{array}$ \\
\hline$r$ & Number of basic industries & $\begin{array}{l}4, \text { agriculture, service } \\
\text { manufacturing, and retail }\end{array}$ \\
\hline$c$ & Number of construction and demolition industries & $\begin{array}{l}8 \text {, one for each building } \\
\text { type }\end{array}$ \\
\hline \multicolumn{3}{|c|}{ Endogenous variables: consumer's problem } \\
\hline & Description & Dimension \\
\hline$\tilde{U}$ & Indirect utility, lower nest of the nested logit & $i, j, k, f$ \\
\hline$V$ & Composite utility, higher nest of the nested logit & $w, f$ \\
\hline$\Psi$ & Net full income & $i, j, f$ \\
\hline$M$ & Unearned Income & $f$ \\
\hline Z & Quantities of retail goods & $z$ \\
\hline$b$ & Floor space & $i, j, k$ \\
\hline
\end{tabular}




\begin{tabular}{|l|l|l|}
\hline$p_{\Re z}$ & Price of retail good & $z$ \\
\hline$\psi$ & Full delivered price of retail & $z$ \\
\hline$R$ & Rents & $i, k+b$ \\
\hline$w$ & Hourly gross wage & $j, f$ \\
\hline$g^{\text {shoppingworking }}$ & Expected travel time for one round trip & $i, z ; i, j$ \\
\hline$G^{\text {shoppingworking }}$ & Monetary travel costs for one round trip & $i, z ; i, j$ \\
\hline$P^{L}$ & $\begin{array}{l}\text { Nested multinomial logit choice probabilities, } \\
\text { lower nest }\end{array}$ & $i, j, k, f, w$ \\
\hline$P^{H}$ & $\begin{array}{l}\text { Nested multinomial logit choice probabilities, } \\
\text { higher nest }\end{array}$ & $f, w$ \\
\hline$P$ & Nested multinomial logit choice probabilities & $i, j, k, f, w$ \\
\hline \hline
\end{tabular}

\section{Endogenous variables: producer's problem}

\begin{tabular}{|l|l|l|}
\multicolumn{1}{|c|}{ Description } & \multicolumn{1}{c|}{ Dimension } \\
\hline \hline$X$ & Total output & $j, f, r+c$ \\
\hline$L$ & Labor demand & $b, f, r+c$ \\
\hline$B$ & Commercial and industrial floor space & $j, r+c$ \\
\hline$K$ & Capital & $r, j, r+c, j$ \\
\hline$Y$ & Intermediate Inputs & $j, r+c$ \\
\hline$p$ & Output prices & $r, j, j$ \\
\hline$\hat{p}$ & Prices of intermediate inputs net of freight cots & $r$ \\
\hline \hline
\end{tabular}




\begin{tabular}{|c|c|c|}
\hline \multicolumn{3}{|c|}{ Endogenous variables: landlord's problem } \\
\hline & Description & Dimension \\
\hline$q$ & $\begin{array}{l}\text { Choice probabilities landlord: decision whether to } \\
\text { rent a unit floor space }\end{array}$ & $i, k+b$ \\
\hline$\omega$ & Expected rental profit & $i, k+b$ \\
\hline
\end{tabular}

\begin{tabular}{|c|c|c|}
\hline \multicolumn{3}{|c|}{ Endogenous variables: developer's problem } \\
\hline & Description & Dimension \\
\hline$Q$ & $\begin{array}{l}\text { Choice probabilities developer: decision to } \\
\text { construct or demolish a unit of building stock }\end{array}$ & $i, k+b$ \\
\hline$S$ & Building stocks & $i, k+b$ \\
\hline$V$ & Real estate value & $i, k+b$ \\
\hline
\end{tabular}

Exogenous variables and parameters: consumer's problem

\begin{tabular}{|l|l|l|}
\multicolumn{1}{|l|}{ Description } & \multicolumn{1}{c|}{ Dimension } \\
\hline \hline$N$ & $\begin{array}{l}\text { Total number of individuals for each skill class } \\
\text { group } \\
\text { Annual time endowment }\end{array}$ & $f, f$ \\
\hline$d$ & Number of commute days (workdays) & $j, j, f$ \\
\hline$c$ & $\begin{array}{l}\text { Number of retail trips needed to buy one unit of } \\
\text { good }\end{array}$ & $i, j, z, f$ \\
\hline$\ell$ & $\begin{array}{l}\text { Intrinsic attractiveness of retail locations } \\
\text { Share parameter Cobb-Douglas (goods); utility } \\
\text { function }\end{array}$ & $f$ \\
\hline$\beta$ & $\begin{array}{l}\text { Share parameter Cobb-Douglas (floor space); } \\
\text { utility function }\end{array}$ & $f$ \\
\hline$\eta$ & Coefficient of elasticity between retail location & $f$ \\
\hline
\end{tabular}




\begin{tabular}{|c|c|c|}
\hline$\vartheta$ & Tax rate for employed & $f$ \\
\hline$\vartheta^{u}$ & Tax rate for unemployed & $f$ \\
\hline$E^{L}$ & $\begin{array}{l}\text { Intrinsic attractiveness of choice bundle: } \\
\text { residency, place of work, and building type }\end{array}$ & $i, j, k, f, w$ \\
\hline$E^{H}$ & $\begin{array}{l}\text { Intrinsic attractiveness of choice bundle: work } \\
\text { status }\end{array}$ & $f, w$ \\
\hline$\lambda^{L}$ & $\begin{array}{l}\text { Dispersion parameter for the lower nest of the } \\
\text { nested multinomial logit probability }\end{array}$ & $f, w$ \\
\hline$\lambda^{H}$ & $\begin{array}{l}\text { Dispersion parameter for the higher nest of the } \\
\text { nested multinomial logit probability }\end{array}$ & $f$ \\
\hline$\Theta$ & Annual income inflow from outside the model & $f$ \\
\hline$\xi$ & $\begin{array}{l}\text { Share of the total asset income owns by each skill } \\
\text { class }\end{array}$ & $f$ \\
\hline \multicolumn{3}{|c|}{ Exogenous variables and parameters: producer's problem } \\
\hline & Description & Dimension \\
\hline$\rho$ & Price of capital & \\
\hline$v$ & $\begin{array}{l}\text { Cost share of capital in the Cobb-Douglas } \\
\text { production function }\end{array}$ & $r+c$ \\
\hline$\delta$ & $\begin{array}{l}\text { Cost share of labor in the Cobb-Douglas } \\
\text { production function }\end{array}$ & $r+c$ \\
\hline$\mu$ & $\begin{array}{l}\text { Cost share of floor space in the Cobb-Douglas } \\
\text { production function }\end{array}$ & $r+c$ \\
\hline$\gamma$ & $\begin{array}{l}\text { Cost share of intermediate inputs in the Cobb- } \\
\text { Douglas production function }\end{array}$ & $r, r+c$ \\
\hline$\kappa$ & $\begin{array}{l}\text { Intrinsic attractiveness of a particular type of } \\
\text { labor }\end{array}$ & $j, f, r+c$ \\
\hline$\chi$ & $\begin{array}{l}\text { Intrinsic attractiveness of a particular type of } \\
\text { floor space }\end{array}$ & $b, f, r+c$ \\
\hline
\end{tabular}




\begin{tabular}{|l|l|l|}
\hline$v$ & $\begin{array}{l}\text { Intrinsic attractiveness of a particular type of } \\
\text { intermediate input }\end{array}$ & $r, j, r+c, j$ \\
\hline$\theta$ & $\begin{array}{l}\text { Coefficient of elasticity between particular type } \\
\text { of labor }\end{array}$ & $r+c$ \\
\hline$\varsigma$ & $\begin{array}{l}\text { Coefficient of elasticity between particular type } \\
\text { of floor space }\end{array}$ & $r+c$ \\
\hline$\varepsilon$ & $\begin{array}{l}\text { Coefficient of elasticity between particular type } \\
\text { of intermediate input }\end{array}$ & $r, r+c$ \\
\hline \hline
\end{tabular}

Exogenous variables and parameters: landlord's problem

\begin{tabular}{|l|l|l|}
\multicolumn{2}{|l|}{ Description } & \multicolumn{1}{c|}{ Dimension } \\
\hline \hline$D$ & $\begin{array}{l}\text { Costs of building maintenance common to all } \\
\text { landlords }\end{array}$ & $i, k+b$ \\
\hline$\phi$ & $\begin{array}{l}\text { Dispersion parameter for the idiosyncratic } \\
\text { maintenance costs }\end{array}$ & $i, k+b$ \\
\hline \hline
\end{tabular}

Exogenous variables and parameters: developer's problem

\begin{tabular}{|l|l|l|}
\multicolumn{2}{|l|}{ Description } & \multicolumn{1}{c|}{ Dimension } \\
\hline \hline$F$ & $\begin{array}{l}\text { Construction and demolition costs common to all } \\
\text { developers }\end{array}$ & $i, k+b$ \\
\hline$\Phi$ & $\begin{array}{l}\text { Dispersion parameter for the idiosyncratic } \\
\text { construction and demolition costs }\end{array}$ & $i, k+b$ \\
\hline$m$ & $\begin{array}{l}\text { Structural density of each building type (square } \\
\text { feet of floor space per acre) }\end{array}$ & $k+b$ \\
\hline
\end{tabular}




\section{Tables}

Table 1. Population Distribution for LUSTRE Baseline (1a) By Skill Class

\begin{tabular}{|ccccc|}
\hline $\begin{array}{c}\text { Skill } \\
\text { class }\end{array}$ & Population & \% of total & $\begin{array}{c}\text { Number } \\
\text { employed }\end{array}$ & \% employed \\
\hline 1 & $1,480,873$ & 35.8 & 830,601 & 56.10 \\
2 & 941,310 & 22.7 & 738,659 & 78.50 \\
3 & $1,244,120$ & 30.1 & $1,144,755$ & 92.00 \\
4 & 472,832 & 11.4 & 461,014 & 97.50 \\
Total & $4,139,134$ & & 3,175028 & 76.70 \\
\hline
\end{tabular}


Table 1 (cont.) (1b) By Zone and Skill Class

\begin{tabular}{|c|c|c|c|c|c|c|}
\hline \multirow{2}{*}{$\begin{array}{l}\text { Zone } \\
\text { I }\end{array}$} & \multirow[t]{2}{*}{ Description } & \multicolumn{4}{|c|}{ Prob(Skill|zone) } & \multirow{2}{*}{$\begin{array}{c}\text { Zone } \\
\text { population }\end{array}$} \\
\hline & & $F=1$ & $\mathrm{~F}=2$ & $F=3$ & $\mathrm{~F}=4$ & \\
\hline 1 & DC Downtown & $40.2 \%$ & $22.4 \%$ & $25.7 \%$ & $11.7 \%$ & 62,873 \\
\hline 2 & DC Northwest & $33.5 \%$ & $18.4 \%$ & $27.9 \%$ & $20.2 \%$ & 101,169 \\
\hline 3 & DC Northeast & $51.2 \%$ & $25.7 \%$ & $19.4 \%$ & $3.8 \%$ & 145,394 \\
\hline 4 & DC Southeast & $48.4 \%$ & $26.9 \%$ & $20.3 \%$ & $4.4 \%$ & 93,419 \\
\hline 5 & Montgomery Co. Southwest & $29.4 \%$ & $14.6 \%$ & $26.0 \%$ & $30.1 \%$ & 57,180 \\
\hline 6 & Montgomery Co. Southeast & $39.9 \%$ & $24.0 \%$ & $26.6 \%$ & $9.4 \%$ & 50,848 \\
\hline 7 & Montgomery Co. West & $29.8 \%$ & $19.1 \%$ & $31.2 \%$ & $19.9 \%$ & 137,803 \\
\hline 8 & Montgomery Co. East & $37.8 \%$ & $22.1 \%$ & $28.6 \%$ & $11.5 \%$ & 240,271 \\
\hline 9 & Montgomery Co. Northeast & $32.5 \%$ & $21.6 \%$ & $32.3 \%$ & $13.6 \%$ & 98,539 \\
\hline 10 & Prince George's Co. Northwest & $47.9 \%$ & $27.8 \%$ & $21.5 \%$ & $2.8 \%$ & 175,023 \\
\hline 11 & Prince George's Co. Southwest & $37.9 \%$ & $31.8 \%$ & $28.3 \%$ & $2.1 \%$ & 86,455 \\
\hline 12 & Prince George's Co. Northeast & $31.6 \%$ & $23.8 \%$ & $35.5 \%$ & $9.0 \%$ & 143,984 \\
\hline 13 & Prince George's Co. Southeast & $31.7 \%$ & $24.1 \%$ & $37.6 \%$ & $6.6 \%$ & 136,127 \\
\hline 14 & Frederick Co. & $36.3 \%$ & $26.4 \%$ & $29.5 \%$ & $7.8 \%$ & 128,634 \\
\hline 15 & Carroll Co. & $37.2 \%$ & $24.6 \%$ & $31.6 \%$ & $6.6 \%$ & 97,723 \\
\hline 16 & Howard Co. & $30.3 \%$ & $20.4 \%$ & $34.0 \%$ & $15.2 \%$ & 166,163 \\
\hline 17 & Anne Arundel Co. & $36.5 \%$ & $24.7 \%$ & $30.3 \%$ & $8.6 \%$ & 334,138 \\
\hline 18 & Calvert Co. & $35.7 \%$ & $23.2 \%$ & $33.6 \%$ & $7.5 \%$ & 47,935 \\
\hline 19 & Charles Co. & $37.0 \%$ & $24.9 \%$ & $32.3 \%$ & $5.8 \%$ & 135,048 \\
\hline 20 & Arlington East & $41.8 \%$ & $21.9 \%$ & $26.3 \%$ & $10.0 \%$ & 10,373 \\
\hline 21 & Arlington South & $36.6 \%$ & $23.4 \%$ & $30.2 \%$ & $9.8 \%$ & 63,109 \\
\hline 22 & Arlington West & $29.1 \%$ & $18.9 \%$ & $32.1 \%$ & $20.0 \%$ & 72,630 \\
\hline 23 & Alexandria & $33.5 \%$ & $22.1 \%$ & $31.1 \%$ & $13.4 \%$ & 99,163 \\
\hline 24 & Fairfax Co. East & $39.8 \%$ & $22.0 \%$ & $27.1 \%$ & $11.2 \%$ & 114,014 \\
\hline 25 & Fairfax Co. Northeast & $29.3 \%$ & $16.6 \%$ & $29.2 \%$ & $24.9 \%$ & 32,983 \\
\hline 26 & Fairfax Co. South & $32.5 \%$ & $19.8 \%$ & $32.1 \%$ & $15.5 \%$ & 287,343 \\
\hline 27 & Fairfax Co. Northwest & $30.6 \%$ & $17.5 \%$ & $31.0 \%$ & $20.9 \%$ & 263,001 \\
\hline 28 & Loudoun Co. East & $28.3 \%$ & $19.7 \%$ & $35.4 \%$ & $16.6 \%$ & 95,607 \\
\hline 29 & Loudoun Co. West & $36.0 \%$ & $19.1 \%$ & $28.1 \%$ & $16.8 \%$ & 16,948 \\
\hline 30 & Prince William Co. South & $34.1 \%$ & $24.1 \%$ & $32.8 \%$ & $8.9 \%$ & 144,024 \\
\hline 31 & Prince William Co. North & $34.6 \%$ & $26.0 \%$ & $32.0 \%$ & $7.4 \%$ & 67,302 \\
\hline 32 & $\begin{array}{l}\text { Stafford/Fredericksburg Co. } \\
\text { North }\end{array}$ & $35.8 \%$ & $24.0 \%$ & $31.8 \%$ & $8.4 \%$ & 58,809 \\
\hline 33 & Fauquier Co. & $38.3 \%$ & $23.0 \%$ & $28.5 \%$ & $10.2 \%$ & 36,623 \\
\hline 34 & Clarke Co. & $46.0 \%$ & $25.8 \%$ & $23.4 \%$ & $4.8 \%$ & 37,400 \\
\hline 35 & $\begin{array}{l}\text { Stafford/Fredericksburg Co. } \\
\text { South }\end{array}$ & $41.3 \%$ & $25.6 \%$ & $27.6 \%$ & $5.5 \%$ & 60,220 \\
\hline 36 & King George Co. & $41.9 \%$ & $26.6 \%$ & $25.6 \%$ & $5.9 \%$ & 10,914 \\
\hline Max & & $51.2 \%$ & $31.8 \%$ & $37.6 \%$ & $30.1 \%$ & 334,138 \\
\hline Min & & $28.3 \%$ & $14.6 \%$ & $19.4 \%$ & $2.1 \%$ & 10914 \\
\hline
\end{tabular}


Table 2. Wage and Income Information for LUSTRE Baseline

\begin{tabular}{|c|c|c|c|}
\hline & $\begin{array}{l}\text { Average income }^{a} \\
\quad(2000 \$ / \text { year })\end{array}$ & $\begin{array}{c}\text { Average hourly } \\
\text { wage rate } \\
(2000 \$ / \text { year })\end{array}$ & Income tax rates \\
\hline Skill class 1 & $15,778.7$ & 6.8 & $14.3 \%$ \\
\hline Skill class 2 & $25,814.8$ & 14.1 & $16.6 \%$ \\
\hline Skill class 3 & $43,942.8$ & 22.5 & $22.3 \%$ \\
\hline Skill class 4 & $91,804.7$ & 47.0 & $31.5 \%$ \\
\hline
\end{tabular}

${ }^{a}$ Net of income tax and commuting costs. 
Table 3. A Sampling of LNYW Programs

\begin{tabular}{|c|c|}
\hline Programs & Description \\
\hline $\begin{array}{l}\text { Baltimore Live Near Your Work } \\
\text { Program }\end{array}$ & $\begin{array}{l}\$ 2,000 \text { grant for closing costs to employees of participating } \\
\text { employers who buy homes in targeted neighborhoods. City of } \\
\text { Baltimore matches } 50 \% \text { of employer grant up to } \$ 1,000 \text {. } \\
\text { Home purchase benefits of up to } \$ 18,500 \text { to employees of Johns } \\
\text { Hopkins University who locate in selected neighborhoods. }\end{array}$ \\
\hline $\begin{array}{l}\text { Minneapolis/University of Minnesota } \\
\text { Live Near Your Work }\end{array}$ & $\begin{array}{l}\text { Grants and deferred or revolving loans of up to } \$ 35,000 \text { for } \\
\text { purchase, maintenance, or repair of homes in the University } \\
\text { District. }\end{array}$ \\
\hline $\begin{array}{l}\text { DC Live Near Your Work, in } \\
\text { partnership with Gallaudet and } \\
\text { American Universities }\end{array}$ & $\begin{array}{l}\$ 6,000 \text { grant from employer matched by } \$ 6,000 \text { grant from the } \\
\text { city available to employees who purchase homes less than } 2.5 \\
\text { miles from their jobsite. } \\
\text { Pilot program (2012) offered to } 10 \text { employees on each campus. }\end{array}$ \\
\hline $\begin{array}{l}\text { DC Employer Assisted Housing } \\
\text { Program (EAHP) }\end{array}$ & $\begin{array}{l}\text { Grants and deferred loans of up to } \$ 11,500 \text { to employees of the } \\
\text { District of Columbia government who are first-time homebuyers } \\
\text { in Washington, DC. }\end{array}$ \\
\hline $\begin{array}{l}\text { City of Alexandria Moderate Income } \\
\text { Ownership }\end{array}$ & $\begin{array}{l}\text { No-interest, deferred-payment financing of up to } \$ 30,000 \text { for } \\
\text { first-time homeowners who live or work in Alexandria. } \\
\text { Additional assistance to police officers and sheriff's deputies } \\
\text { who live in designated neighborhoods. } 1 \% \text { interest loans up to } \\
\$ 5,000 \text { for public school employees who purchase homes in the } \\
\text { City of Alexandria. }\end{array}$ \\
\hline \multicolumn{2}{|l|}{ Arlington County, VA } \\
\hline Live Near Your Work Program & $\begin{array}{l}\text { Loans of up to } \$ 5,400 \text { available to county and school board } \\
\text { employees, forgivable after } 3 \text { years. }\end{array}$ \\
\hline $\begin{array}{l}\text { Moderate Income Purchase } \\
\text { Assistance Program }\end{array}$ & $\begin{array}{l}\text { Up to } \$ 25,000 \text { mortgage assistance to moderate-income } \\
\text { households with at least one household member employed by } \\
\text { the county or school system. }\end{array}$ \\
\hline
\end{tabular}


Table 4. Welfare Gains and Revenue Collected under LNYW Policies

\begin{tabular}{l|ccc|c|c|c}
\hline & $\begin{array}{c}\text { Annual } \\
\text { subsidy } \\
(2000 \$)\end{array}$ & $\begin{array}{c}\text { Total } \\
\text { subsidy } \\
\text { (thousands } \\
\text { of \$/year) }\end{array}$ & $\begin{array}{c}\text { Per } \\
\text { capita } \\
\text { subsidy } \\
\text { (\$/year) }\end{array}$ & $\begin{array}{c}\text { Per } \\
\text { capita } \\
\text { welfare } \\
\text { gains } \\
\text { \$/year) }\end{array}$ & $\begin{array}{c}\text { Net } \\
\text { welfare } \\
\text { gains per } \\
\text { capita }\end{array}$ & $\begin{array}{c}\text { Ratio of } \\
\text { net } \\
\text { welfare to } \\
\text { subsidy }\end{array}$ \\
\hline \hline Beltway & 260 & 47,558 & 11.49 & 9.75 & -1.74 & $-15.13 \%$ \\
Beltway & 520 & 96,887 & 23.41 & 19.80 & -3.60 & $-15.39 \%$ \\
Beltway & 780 & 148,008 & 35.76 & 30.13 & -5.63 & $-15.75 \%$ \\
Beltway12 & 520 & 56,496 & 13.65 & 11.01 & -2.64 & $-19.33 \%$ \\
All zones & 520 & 553,671 & 133.76 & 121.33 & -12.44 & $-9.30 \%$
\end{tabular}

Table 5. Welfare Decompositions for LNYW Policies (5a) Beltway Policy Evaluated at a \$520 Annual Subsidy

\begin{tabular}{c|c|ccccccc}
\hline & $\begin{array}{c}\text { Welfare } \\
\text { gains } \\
\text { per } \\
\text { capita } \\
\text { (\$/year) }\end{array}$ & $\begin{array}{l}\text { Wage } \\
\text { income }\end{array}$ & $\begin{array}{c}\text { Nonwage } \\
\text { income }\end{array}$ & Price & Rent & $\begin{array}{c}\text { Commute } \\
\text { costs }\end{array}$ & $\begin{array}{c}\text { Other } \\
\text { driving } \\
\text { costs }\end{array}$ & $\begin{array}{c}\text { Correction } \\
\text { term }\end{array}$ \\
\hline \hline Skill class 1 & 21.6 & 6.5 & 23.91 & -8.2 & -5.5 & 0.06 & -0.002 & 5 \\
Skill class 2 & 10.6 & 20.5 & 6.83 & -10.7 & -8.2 & 0.05 & -0.04 & 1.3 \\
Skill class 3 & 17.9 & 37.3 & 7.64 & -17 & -11.8 & 0.14 & -0.05 & 1.9 \\
Skill class 4 & 37.0 & 79.5 & 15.47 & -32.2 & -27.6 & 0.16 & -0.16 & 2.2 \\
\hline $\begin{array}{c}\text { Pop- } \\
\text { weighted } \\
\text { mean }\end{array}$ & 19.7 & 27.3 & 12.87 & -14.2 & -10.5 & 0.09 & -0.04 & \\
\hline
\end{tabular}


Table 5 (cont.)

(5b) Beltway12 Policy Evaluated at \$520 Annual Subsidy

\begin{tabular}{c|c|ccccccc}
\hline & $\begin{array}{c}\text { Welfare } \\
\text { gains } \\
\text { per } \\
\text { capita } \\
\text { (\$/year) }\end{array}$ & $\begin{array}{l}\text { Wage } \\
\text { income }\end{array}$ & $\begin{array}{c}\text { Nonwage } \\
\text { income }\end{array}$ & Price & Rent & $\begin{array}{c}\text { Commute } \\
\text { costs }\end{array}$ & $\begin{array}{c}\text { Other } \\
\text { driving } \\
\text { costs }\end{array}$ & $\begin{array}{c}\text { Correction } \\
\text { term }\end{array}$ \\
\hline \hline Skill class 1 & 17.1 & 3.5 & 14.16 & -5 & -3.3 & 0.03 & 0.003 & 7.8 \\
Skill class 2 & 8.8 & 12 & 4.02 & -6.5 & -5 & 0.02 & -0.02 & 4.3 \\
Skill class 3 & 4.9 & 23.2 & 4.52 & -10.4 & -6.9 & 0.11 & -0.02 & -5.6 \\
Skill class 4 & 11.59 & 48.8 & 9.14 & -20 & -15.3 & 0.11 & -0.07 & -11.1 \\
\hline $\begin{array}{c}\text { Pop- } \\
\text { weighted } \\
\text { mean }\end{array}$ & 10.9 & 16.5 & 7.64 & -8.7 & -6.1 & 0.06 & -0.02 & \\
\hline
\end{tabular}

Table 5 (cont.)

(5c) LNYW All-Zones Policy Evaluated at \$520 Annual Subsidy

\begin{tabular}{c|c|cccccccc}
\hline & $\begin{array}{c}\text { Welfare } \\
\text { gains } \\
\text { per } \\
\text { capita } \\
\text { (\$/year) }\end{array}$ & $\begin{array}{l}\text { Wage } \\
\text { income }\end{array}$ & $\begin{array}{c}\text { Nonwage } \\
\text { income }\end{array}$ & Price & Rent & $\begin{array}{c}\text { Commute } \\
\text { costs }\end{array}$ & $\begin{array}{c}\text { Other } \\
\text { driving } \\
\text { costs }\end{array}$ & $\begin{array}{c}\text { Correction } \\
\text { term }\end{array}$ \\
\hline \hline & & & & & & & & \\
Skill class 1 & 130.6 & 34.8 & 143.23 & -42.9 & -27.2 & -0.06 & 0.3 & 22.4 \\
Skill class 2 & 66.6 & 108.8 & 40.62 & -54.4 & -44.3 & -0.05 & 0.51 & 15.4 \\
Skill class 3 & 113 & 204.1 & 45.84 & -84.8 & -74.5 & -0.14 & 0.94 & 21.6 \\
Skill class 4 & 222.5 & 444.1 & 92.58 & -166 & -155 & -0.16 & 1.81 & 5.9 \\
\hline $\begin{array}{c}\text { Pop- } \\
\text { weighted } \\
\text { mean }\end{array}$ & 121.3 & 149.2 & 76.96 & -72.2 & -59.9 & -0.09 & 0.71 & \\
\hline
\end{tabular}


Table 6. Changes in Transportation Variables under Beltway LNYW Policy

\begin{tabular}{|c|c|c|c|}
\hline & Baseline & Simulation & \% change \\
\hline \multicolumn{4}{|c|}{ VMT and congestion } \\
\hline $\begin{array}{c}\text { Total daily VMT } \\
\text { (millions) }\end{array}$ & 170.96 & 170.89 & -0.041 \\
\hline $\begin{array}{c}\text { Average congestion } \\
\text { costs ( } \phi \text { /mile) }\end{array}$ & 7.445 & 7.439 & -0.081 \\
\hline \multicolumn{2}{|c|}{ Mode split (millions of trips) } \\
\hline SOV & 5.235 & 5.23 & -0.024 \\
\hline HOV & 2.793 & 2.793 & 0.051 \\
\hline Bus & 0.242 & 0.237 & 0.273 \\
\hline Rail & 0.505 & 0.504 & 0.061 \\
\hline Nonmotorized & 0.622 & 0.626 & 0.669 \\
\hline \multicolumn{2}{|c|}{ Average trip distance } & -0.039 \\
\hline Shopping trips & 14.671 & 7.778 & \\
\hline
\end{tabular}


Table 7. Welfare Gains and Revenue Collected under VMT Tax Policies

\begin{tabular}{|c|c|c|c|c|c|c|}
\hline & $\begin{array}{c}\text { Tax rate } \\
(2000 \phi / \text { mile })\end{array}$ & $\begin{array}{l}\text { Total tax } \\
\text { collection } \\
\text { (millions of } \\
2000 \$ / \text { year) }\end{array}$ & $\begin{array}{c}\text { Per capita tax } \\
\text { collection }(\$ / \text { year })\end{array}$ & $\begin{array}{c}\text { Net } \\
\text { welfare } \\
\text { change } \\
\text { per } \\
\text { capita } \\
\text { (\$/year) }\end{array}$ & $\begin{array}{c}\text { Net } \\
\text { welfare } \\
\text { gains } \\
\text { per } \\
\text { capita } \\
\text { (\$/year) }\end{array}$ & $\begin{array}{c}\text { Ratio of } \\
\text { net } \\
\text { welfare } \\
\text { to tax } \\
\text { collection }\end{array}$ \\
\hline VMT tax & 2 & 348 & 83.99 & -72.64 & 11.35 & 0.135 \\
\hline VMT tax & 3 & 477 & 115.15 & -105.47 & 9.68 & 0.084 \\
\hline VMT tax & 5 & 671 & 162.11 & -165.36 & -3.25 & -0.020 \\
\hline
\end{tabular}

Table 8. Changes in Transportation Variables under VMT Tax Policy

\begin{tabular}{|c|c|c|c|}
\hline Title & Baseline & Simulation & $\%$ change \\
\hline \multicolumn{4}{|c|}{ VMT and congestion } \\
\hline $\begin{array}{l}\text { Total VMT (million } \\
\text { miles per day) }\end{array}$ & 170.96 & 157.78 & -7.71 \\
\hline $\begin{array}{l}\text { Average congestion } \\
\text { costs }(\phi / \text { mile })\end{array}$ & 7.445 & 7.055 & -5.24 \\
\hline \multicolumn{4}{|c|}{ Mode split (millions of trips) } \\
\hline SOV & 5.23 & 4.709 & -10.250 \\
\hline $\mathrm{HOV}$ & 2.79 & 3.22 & 15.404 \\
\hline Bus & 0.24 & 0.25 & 5.013 \\
\hline Rail & 0.50 & 0.53 & 5.956 \\
\hline Nonmotorized & 0.62 & 0.68 & 8.791 \\
\hline \multicolumn{4}{|c|}{ Average Trip Distance (miles) } \\
\hline Work trips & 14.671 & 14.524 & -1.002 \\
\hline Shopping trips & 7.781 & 7.759 & -0.272 \\
\hline
\end{tabular}


Table 9. Welfare Decompositions for VMT Tax Policy

\begin{tabular}{|c|c|c|c|c|c|c|c|c|}
\hline & \multirow{2}{*}{$\begin{array}{c}\text { Welfare } \\
\text { gains } \\
\text { per } \\
\text { capita } \\
\text { (\$/year) }\end{array}$} & \multicolumn{7}{|c|}{ Welfare decomposition (2000\$/year) } \\
\hline & & $\begin{array}{l}\text { Wage } \\
\text { income }\end{array}$ & $\begin{array}{c}\text { Nonwage } \\
\text { income }\end{array}$ & Price & Rent & $\begin{array}{c}\text { Commute } \\
\text { costs }\end{array}$ & $\begin{array}{c}\text { Other } \\
\text { driving } \\
\text { costs }\end{array}$ & $\begin{array}{c}\text { Correction } \\
\text { term }\end{array}$ \\
\hline Skill class 1 & -52.8 & -28.5 & -51.2 & 31.9 & 10.3 & -33.7 & -17.4 & 35.8 \\
\hline Skill class 2 & -53.81 & -84.8 & -14.8 & 41.1 & 17.3 & -63.8 & -24.5 & 75.7 \\
\hline Skill class 3 & -89.91 & -144.1 & -16.3 & 64.1 & 29.6 & -78.2 & -23.7 & 78.7 \\
\hline Skill class 4 & -127.54 & -281.9 & -123.1 & 119.8 & 55.8 & -60.1 & -11.5 & 73.5 \\
\hline $\begin{array}{c}\text { Pop- } \\
\text { weighted } \\
\text { mean }\end{array}$ & -72.7 & -105 & -29.2 & 53.7 & 22.9 & -56.9 & -20.2 & \\
\hline
\end{tabular}

Table 10. Deviations in Net Welfare per Capita by Skill Level

\begin{tabular}{|l|c|c|c|c|c|}
\hline & Skill 1 & Skill 2 & Skill 3 & Skill 4 & Mean \\
\hline \multicolumn{7}{|c|}{ Beltway } \\
\hline Net welfare change (\$/yr) & 21.6 & 10.6 & 17.9 & 37 & 19.7 \\
\hline Deviation from mean & 1.9 & -9.1 & -1.8 & 17.3 & \\
\hline \multicolumn{7}{|c|}{ Beltway12 } \\
\hline Net welfare change & 17.1 & 8.8 & 4.9 & 11.59 & 10.9 \\
\hline Deviation from mean & 6.2 & -2.1 & -6.0 & 0.7 & \\
\hline \multicolumn{7}{|c|}{ LNYW all zones } \\
\hline Net welfare change & 130.6 & 66.6 & 113 & 222.5 & 121.3 \\
\hline Deviation from mean & 9.3 & -54.7 & -8.3 & 101.2 & \\
\hline \multicolumn{7}{|c|}{ VMT tax } \\
\hline Net welfare change & -52.8 & -53.81 & -89.91 & -127.54 & -72.7 \\
\hline Deviation from mean & 19.9 & 18.9 & -17.2 & -54.8 & \\
\hline
\end{tabular}


Table 11. Welfare Distribution

(a) LNYW at a $\$ 520$ (2000\$) Subsidy for All Zones (All Skill Levels)

\begin{tabular}{|l|c|c|c|c|}
\hline & \multicolumn{4}{|c|}{ Skill class } \\
\hline & 1 & 2 & 3 & 4 \\
\hline $\begin{array}{l}\text { Mean per } \\
\text { capita }\end{array}$ & 129.41 & 66.564 & 112.88 & 222.98 \\
\hline Maximum & 169.31 & 86.69 & 172.26 & 304.78 \\
\hline $\begin{array}{l}\text { 75th } \\
\text { percentile }\end{array}$ & 145.52 & 76.988 & 116.78 & 236.98 \\
\hline $\begin{array}{l}\text { 25th } \\
\text { percentile }\end{array}$ & 113.06 & 58.785 & 102.1 & 210.24 \\
\hline \begin{tabular}{l} 
Minimum \\
\hline
\end{tabular} & 80.25 & 28.86 & 64.39 & 145.72 \\
\hline
\end{tabular}

(b) VMT Tax at $\$ 0.02$ per Mile

\begin{tabular}{|l|c|c|c|c|}
\hline & \multicolumn{4}{|c|}{ Skill class } \\
\hline & 1 & 2 & 3 & 4 \\
\hline $\begin{array}{l}\text { Mean per } \\
\text { capita }\end{array}$ & -52.273 & -54.12 & -89.977 & -127.12 \\
\hline Maximum & -34.5 & -17.55 & -22.07 & -56.01 \\
\hline 75th percentile & -47.7 & -44.214 & -80.573 & -115.49 \\
\hline 25th percentile & -56.04 & -59.513 & -96.459 & -136.67 \\
\hline Minimum & -114.32 & -140.12 & -229.98 & -346.38 \\
\hline
\end{tabular}




\section{Figures}

Figure 1. LUSTRE Modeling Region
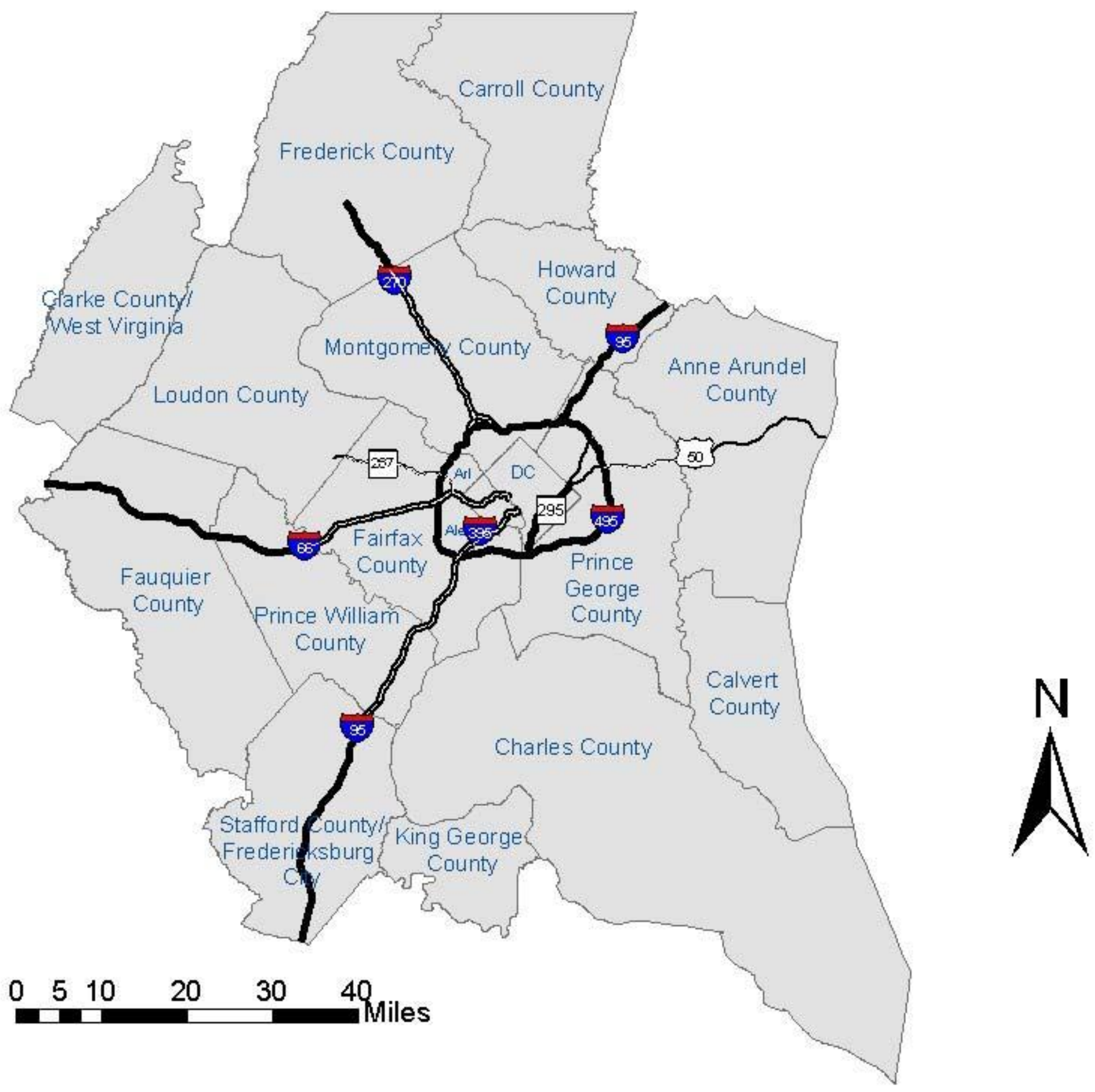
Figure 2. Beltway LNYW

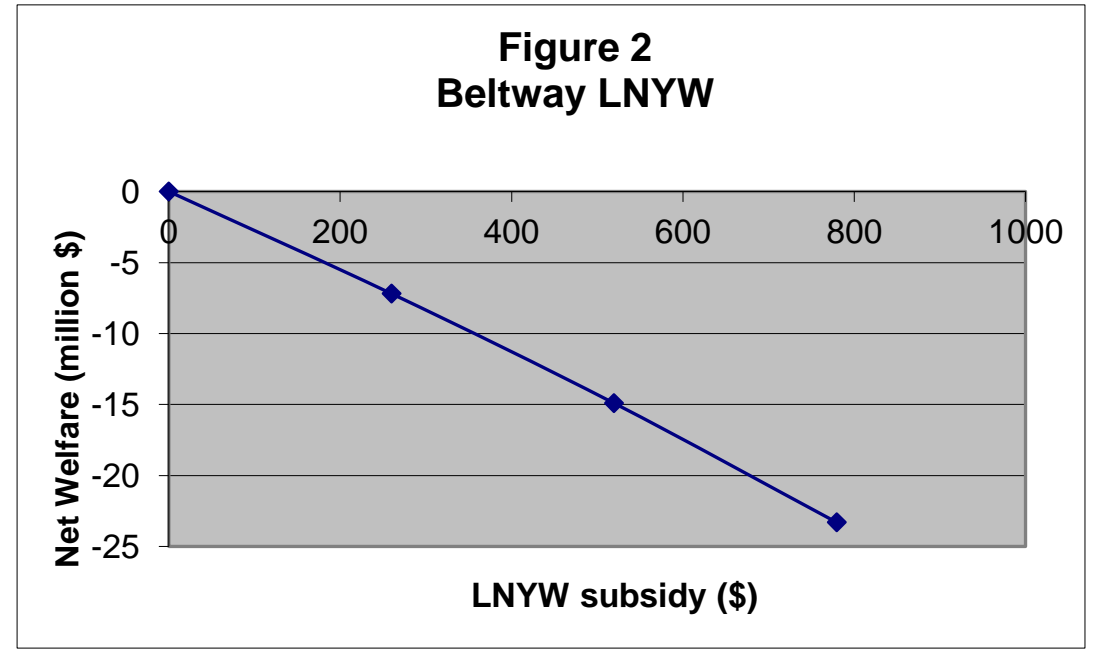

Figure 3

VMT Tax

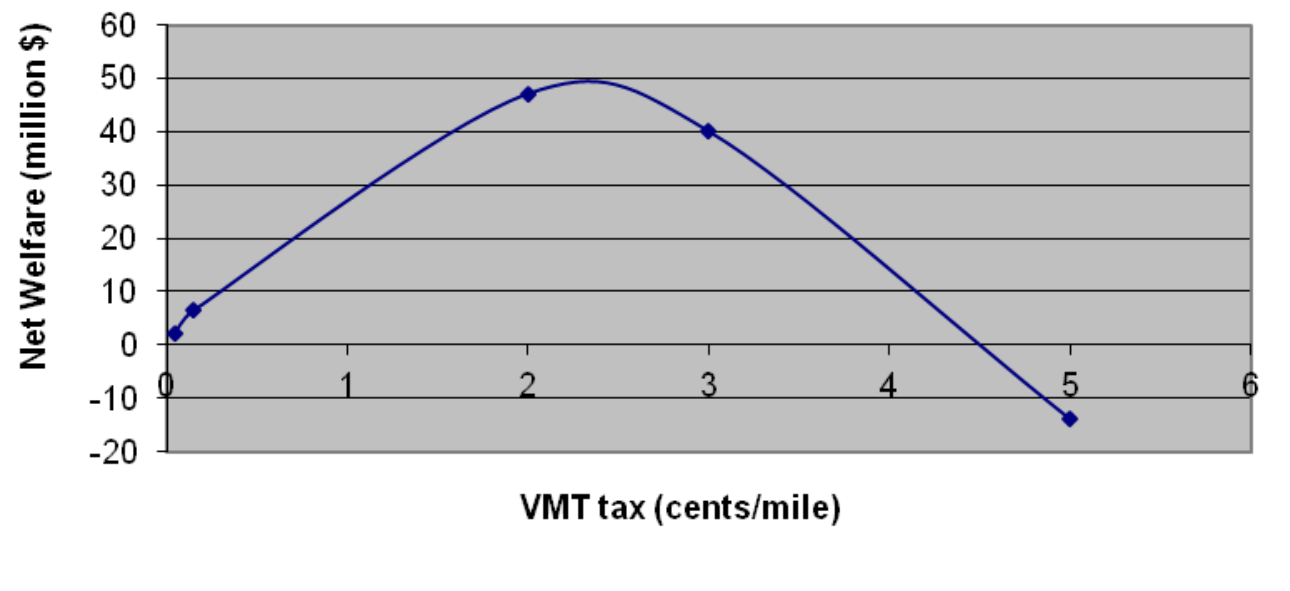


Figure 4a. LNYW, within Beltway Only

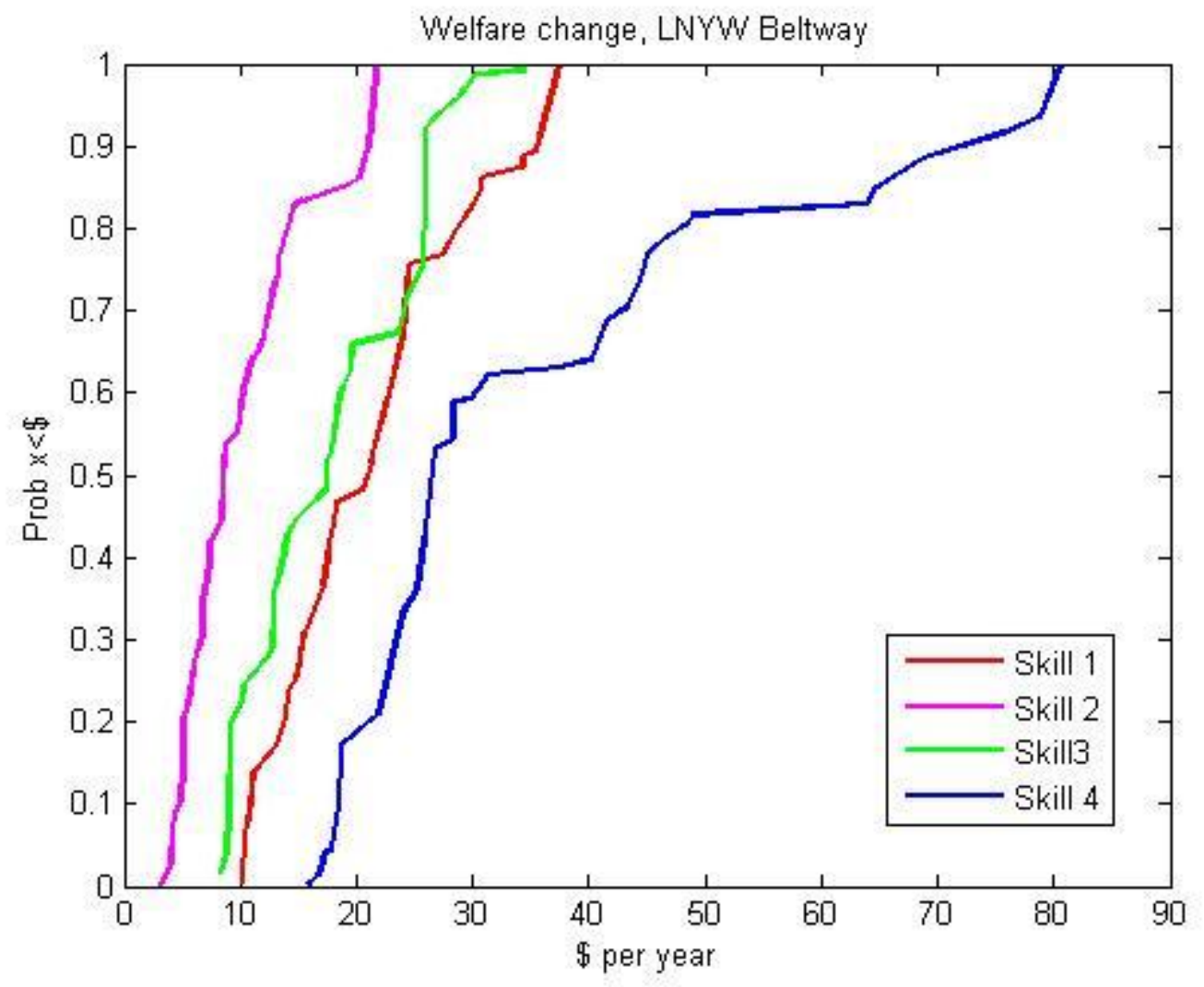


Figure 4b. LNYW, within Beltway, Skill Classes 1 and 2 Only

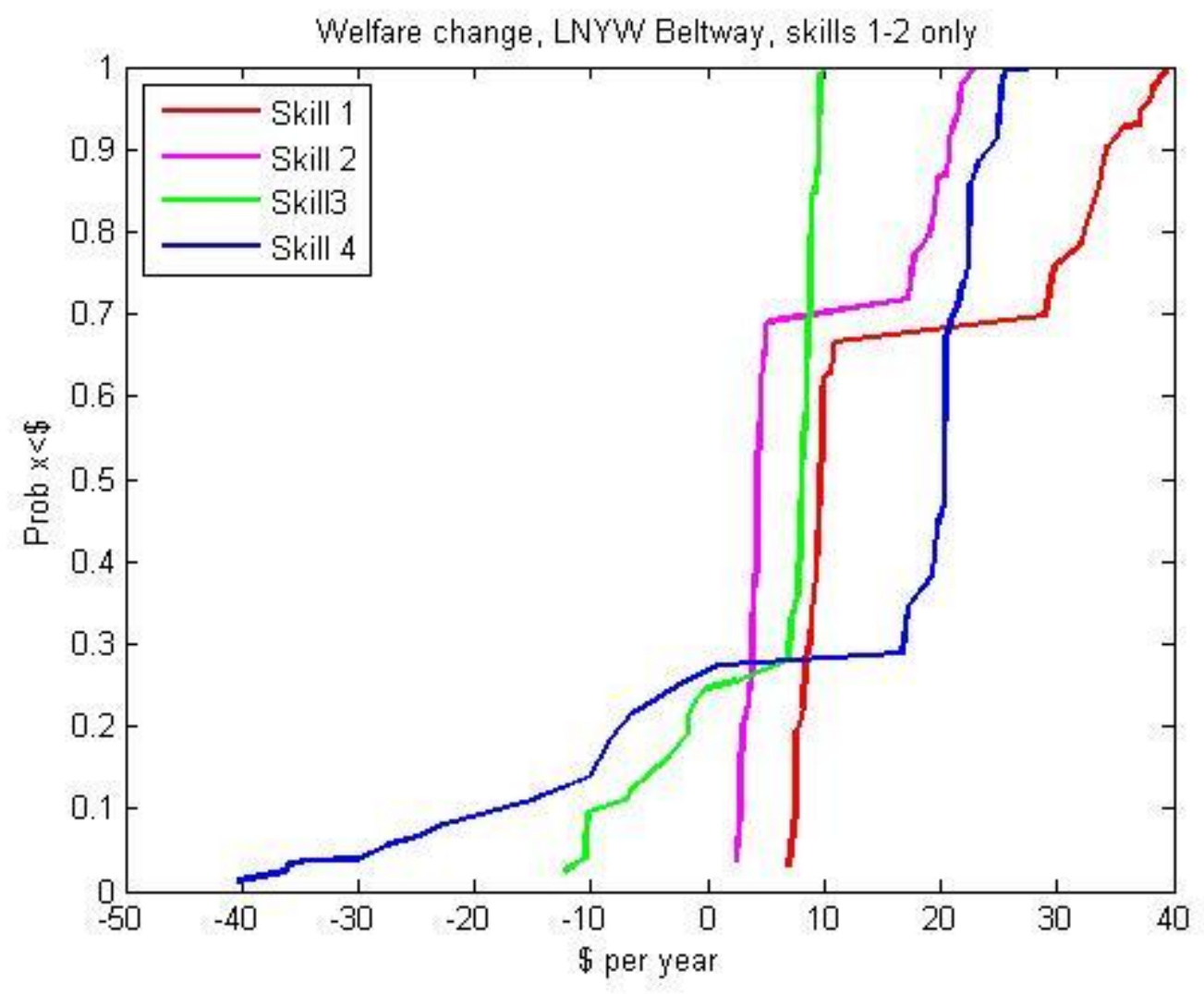


Figure 4c. LNYW, All Zones

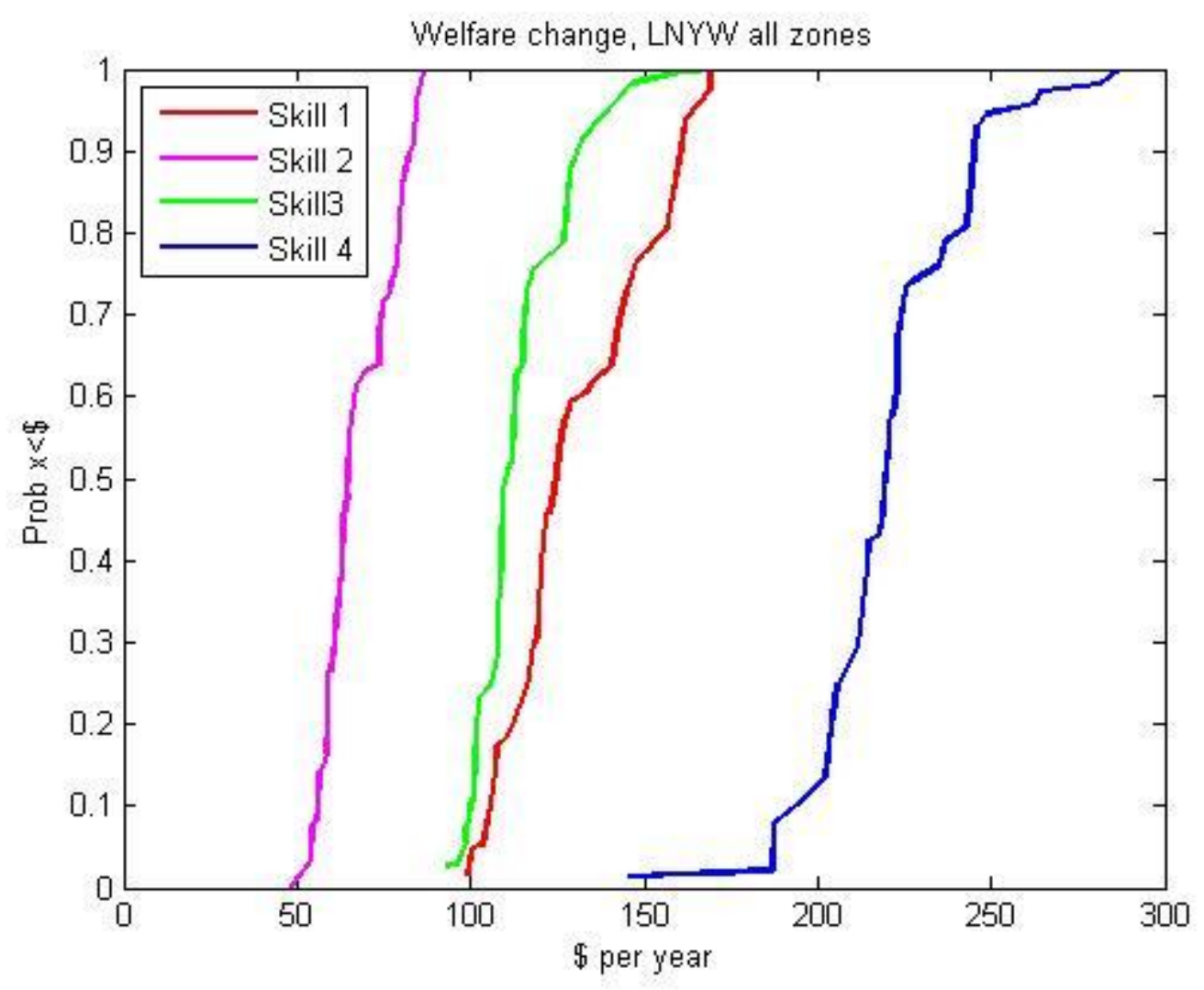


Figure 4d. VMT Tax $\$ 0.02$ per Mile

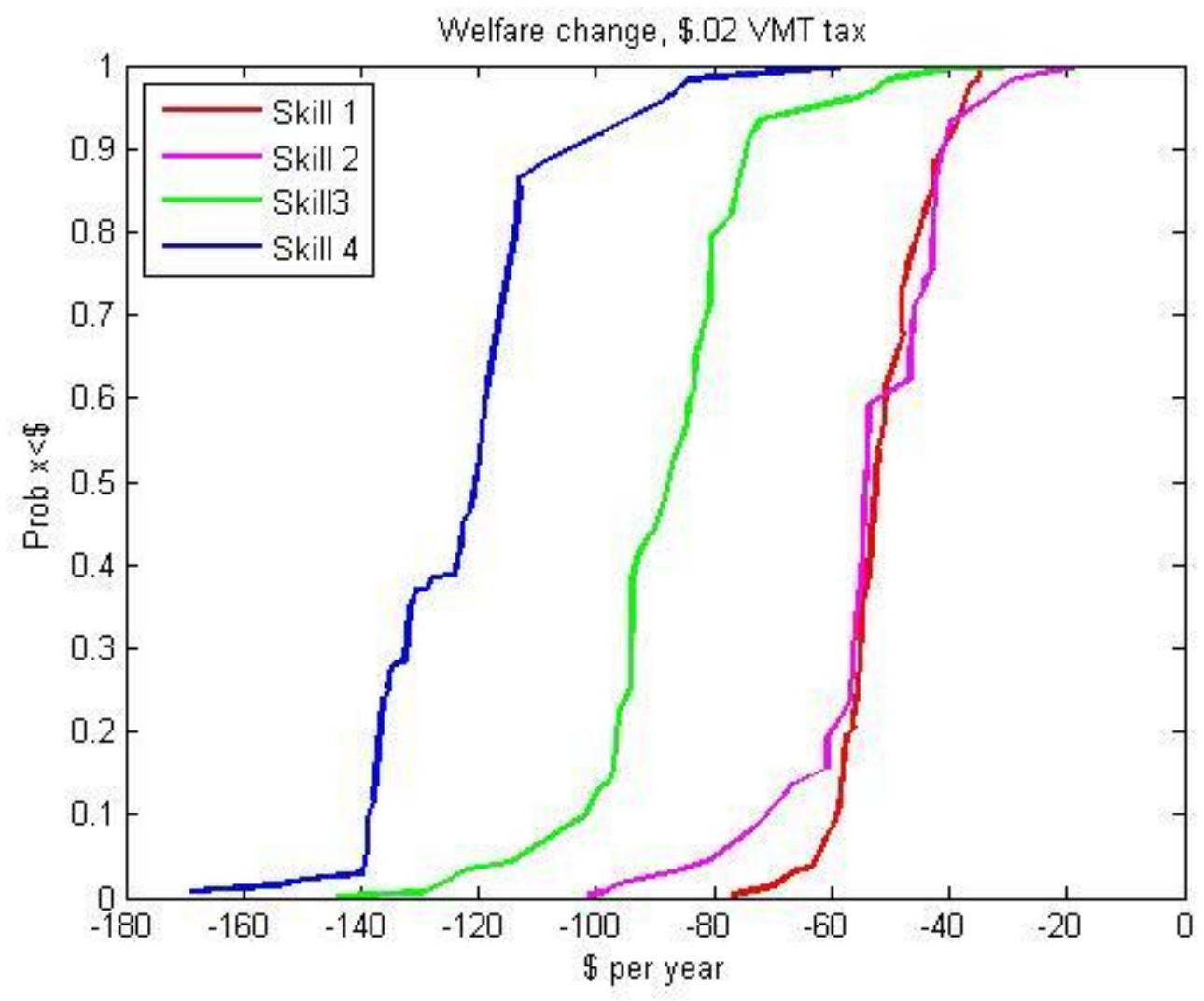


Figure 5a. Beltway LNYW, Benefit Range: $\$ 77.49$

\section{Beltway skill level 1}

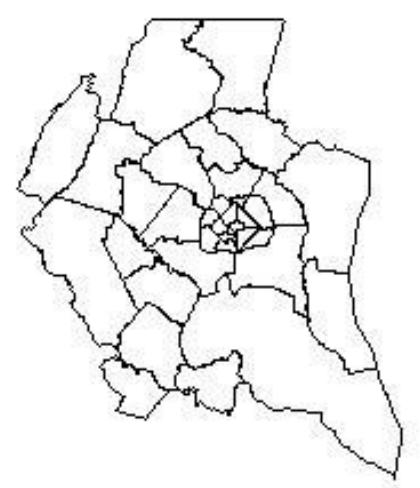

Beltway skill level 2

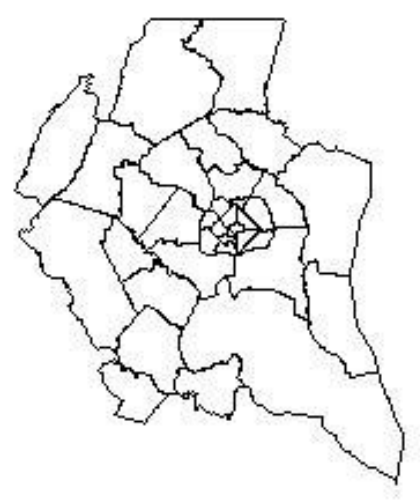

0-15\% $15-30 \%$ 30-70\% 70-85\%85-100\%

Beltway skill level 3

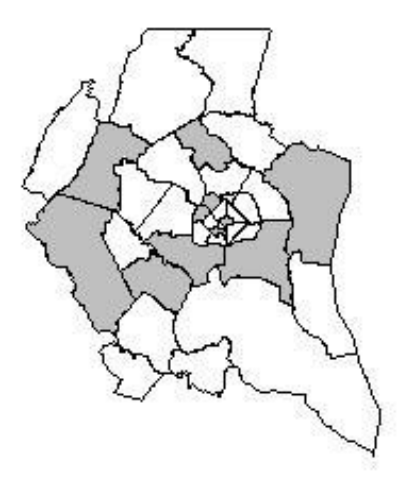

Beltway skill level 4

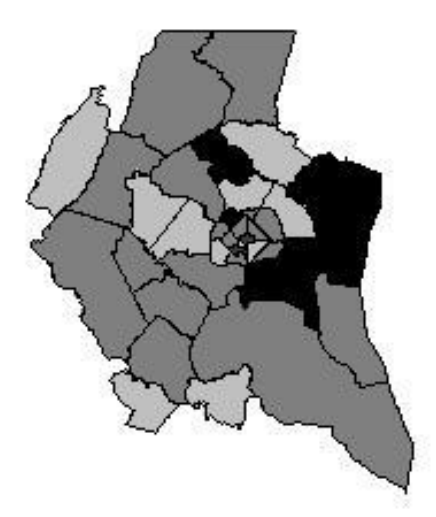


Figure 5b. Beltway LNYW, Skill Levels 1-2 Only, Benefit Range: $\$ 80.05$

\section{Beltway12 skill level 1}

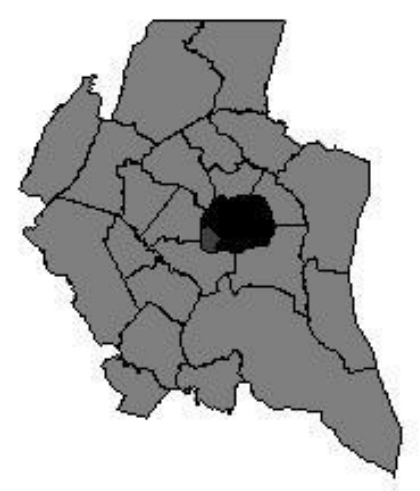

Beltway 12 skill level 2

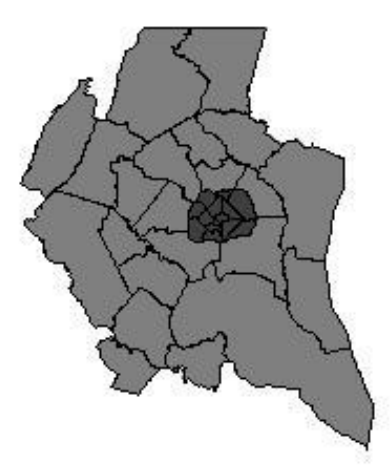

0-15\% $15-30 \%$ 30-70\% 70-85\%85-100\%

Beltway12 skill level 3

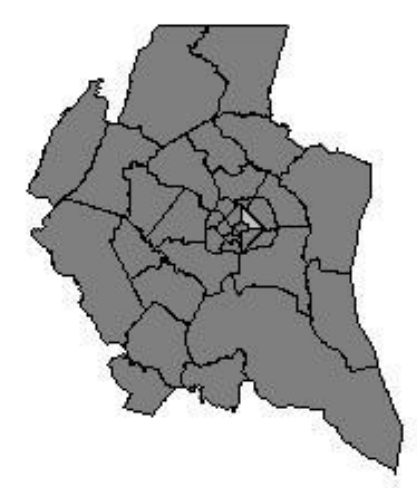

Beltway12 skill level 4

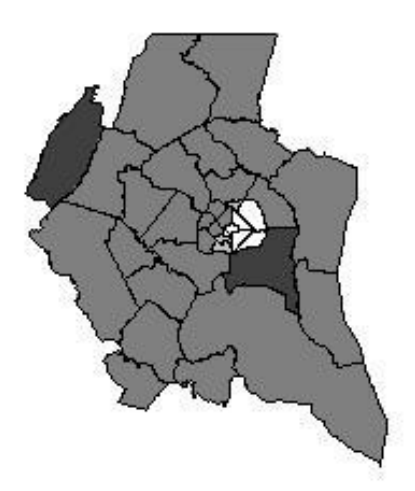


Figure 5c. LNYW Policy, All Zones, Benefit Range: \$248.54

LNMN520 skill level 1

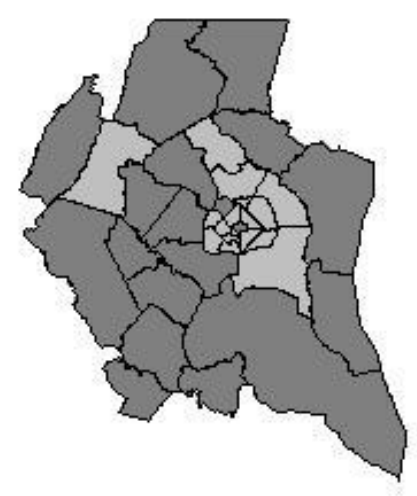

LNMW520 skill level 2

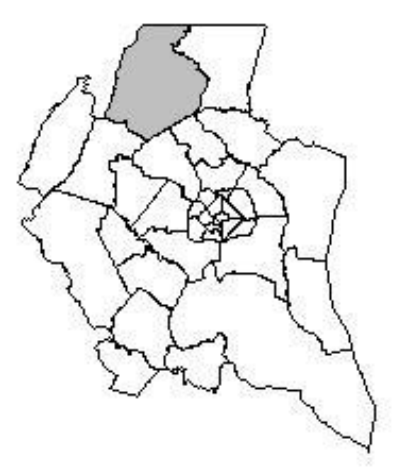

0-15\% $15-30 \%$ 30-70\% 70-85\%85-100\%

LNYW520 skill level 3

LNMW520 skill level 4

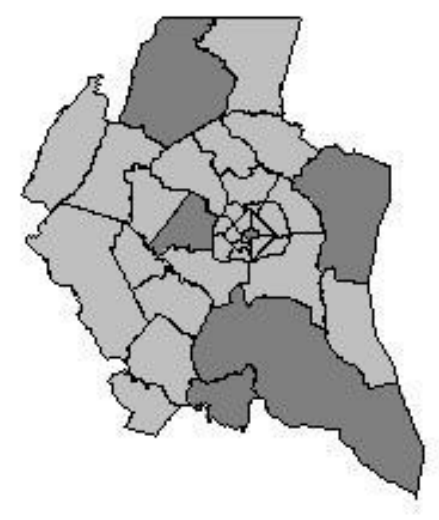

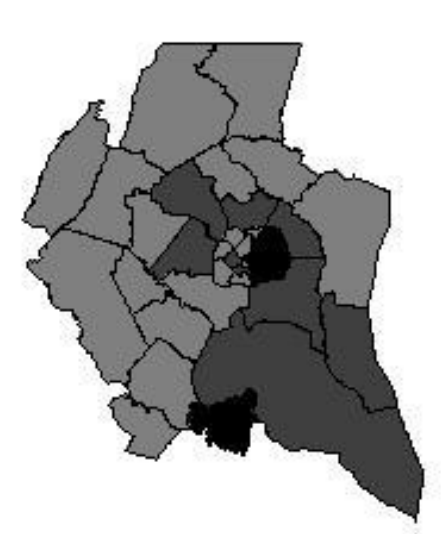


Figure 5d. VMT Tax \$0.02/Mile, Benefit Range: \$151.51

VMTtax02 skill level 1

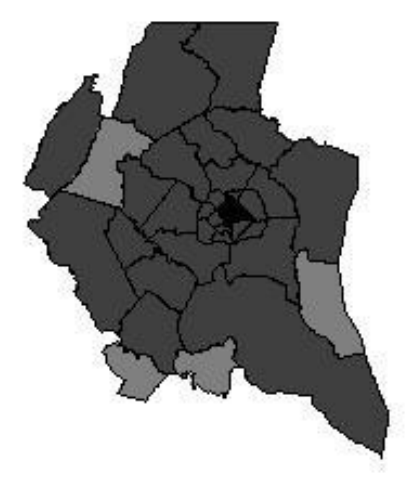

0-15\% $15-30 \%$ 30-70\% 70-85\%85-100\%

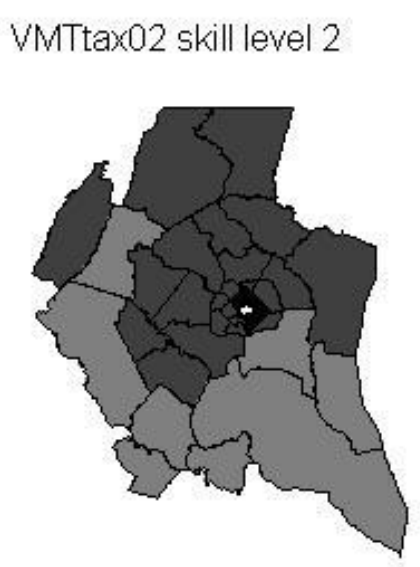

VMTtax02 skill level 3

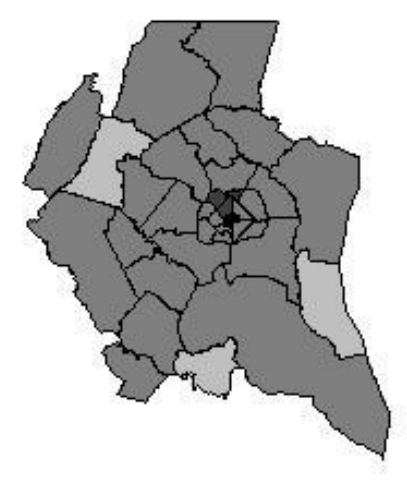

VMTtax02 skill level 4

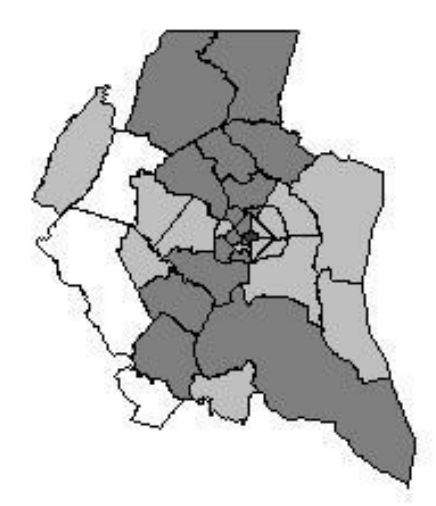

